\title{
في تعليم اللغة العربية للناطقين بغيرها
}

د · خالاد محمد حسين اليوبي (")

يعد تعليم اللغات من أبرز مجالات التعلم في العصر الحاضر؛ ذللك أن اللغة هي وسيلة الفرد الأولى في الحصول على المعلومات و اكتسابه للمعرفة، وتعلم لغة ما نافذة يطل منها المتعلم على الحضارة و الثقافة التي دونت عبر التاريخ بتلك اللغة، وتزداد أهمية تعليم اللغات اليوم بفعل التقدم التقني وما ير افقه من تحولات اقتصادية وثقافية واجتماعية ، إذ غدت اللغة معه قناة التو اصل الأسر ع و الأقوى تأثير ا. وتعليم اللغة الثانية أو محاولة تعلمها ذاتيا لا يكون فاعلا ومؤثز ا بمجرد التلقي النظري عن اللغة بما يحتويه من نصوص لغوية وقو اعد نحوية، و إنما لا بد أن يكون الأساس في ذلك الممارسة التطبيقية و الأداء الفعلي، وتأني الأنشطة اللغوية بأنماطها المتتوعة لتكون أحد أفضل أساليب الممارسة العملية التي يؤديها المتعلم في كل مستوى من مستويات التعلم، و التعليم بالعمل من أهم ما باله تحث عليه نظريات التعليم الحديثة وتؤكده الآثار الإيجابية على المتعلمين. يناقش البحث أنماط الأنشطة اللغوية وتطبيقاتها في تعليم اللغة العربية للناطقين بغيرها، و أثزها في تعزيز إتقان المهارات اللغوية لدى المتعلمين وتتمية كفاءتهم اللغوية بما بسهم في تحقيق أهدافهم من تعلمها.

(") أستاذ مساعد بقسم اللغة العربية و آدابها - كلية الآداب و العلوم الإنسانية جامعة الملك

$$
\text { عبد العزيز. }
$$




\section{أنماط الأنشطة اللغوية}

الأشطة اللغوية:

من الأثثياء الأساسية في تعلم اللغة الثانية أن يجيد المتعلم الاستماع بدقة

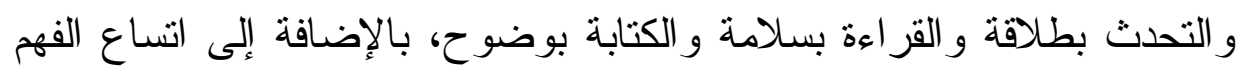

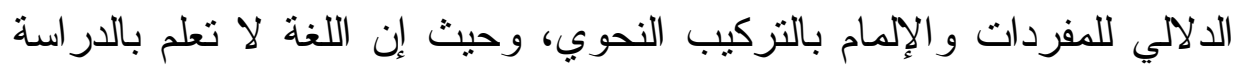

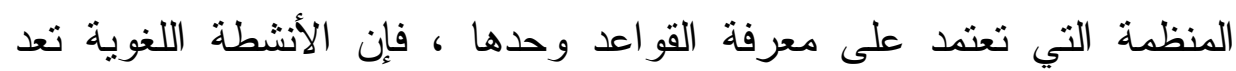

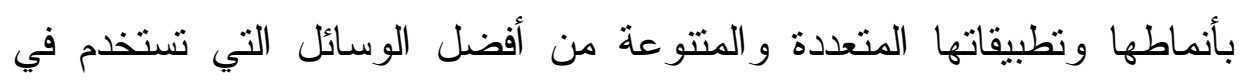
تحقيق أهداف تعلم اللغة وتتمية المهار ات اللغوية لدى المتعلمين (').

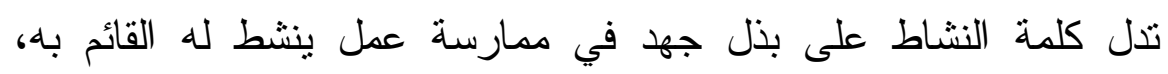

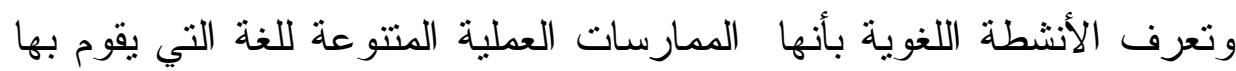

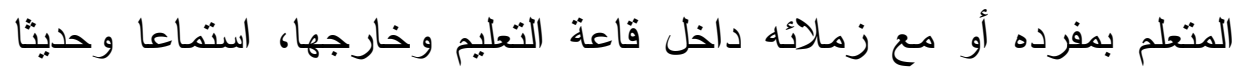

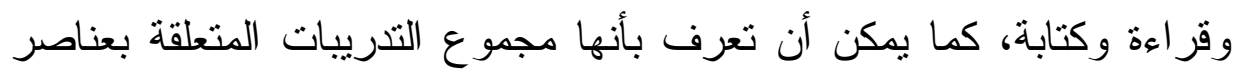

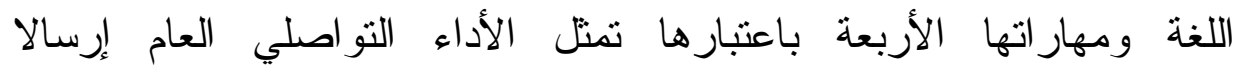

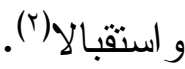

تتقسم الأنشطة اللغوية إلى أنثطة منهجية تمثل الجانب التطبيقي للمواد

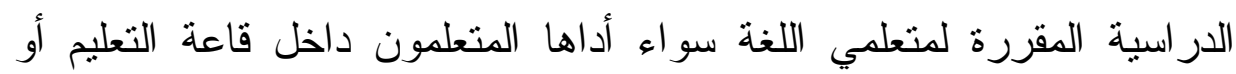

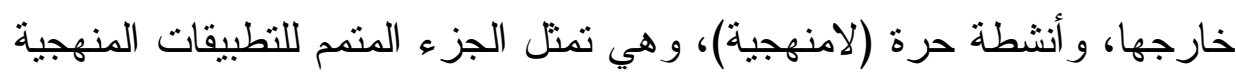
وغالبا ما تؤدى خارج قاعة التعليم، وتهدف إلى المساهمة في تحقيق الكفاية

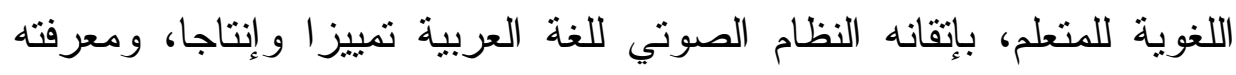
بتر اكيب اللغة وقو اعدها الأساسية نظريا ووظيفيا، والإلمام بقدر ملائم من لإنية مفردات اللغة للفهم والاستعمال، كما تهدف إلى المساهمة في تحقيق الكفاية

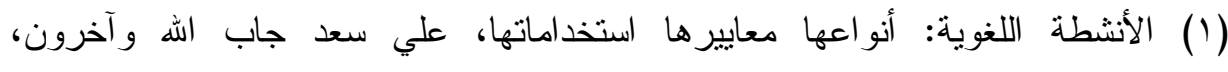

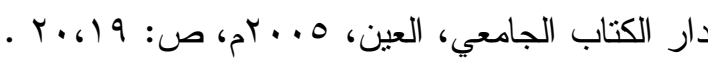

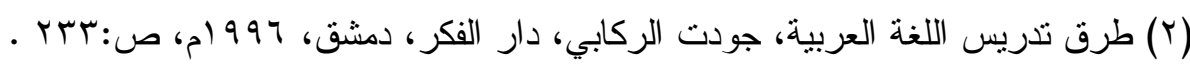

$$
\begin{aligned}
& -117-
\end{aligned}
$$




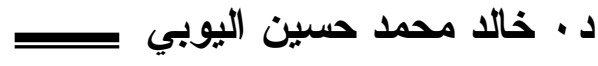

الاتصالية له، وهي قدرته على استخدام اللغة العربية بصورة تلقائية، و التعبير بطلاقة عن أفكاره وخبر اته، مع تمكنه من استيعاب ما يتلقى من اللغة بيسر وسهولة.

وتهدف الأنشطة اللغوية المختلفة إلى تتمية المهار ات اللغوية لاى متعلمي اللغة العربية من خلال تحقيق أهداف المنهج التعليمي و تمكين التعلم بالممارسة اللغوية التطبيقية، وزيادة دافعية المتعلم نحو التعلم والتحصبل اللغوي، وتكوين اتجاهات إيجابية لديه نحو اللغة المتعلمة، وتتمية قدر اته ومساعدته في تثبيت العادات اللغوية الصحيحة واستخدامها في مواقف الحياة الطبيعية، ويتم تطبيقها وفق مجموعة من الأسس العامة التي تساعد في تحقيق أهدافها، ومن

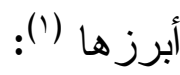
- تعريف المتعلمين بأهداف النشاط اللغوي و المفاهيم المرتبطة به. - الاهتمام بآلية تتفيذ النشاط اللغوي وفهمها بشكل صحيح. - المشاركة الفاعلة للمتعلمين في تتظيم و أداء الأنشطة اللغوية.

\section{أنماط الأشطة اللغوية وتطبيقاتها:}

النمط هو النوع أو الطريقة أو الأسلوب(؟) و وأنماط الأنشطة اللغوية أنو اعها و أساليبها المختلفة التي يقوم بها المتعلم بمفرده أو مع زملائه داخل قاعة التعليم وخارجها، حديثا واستماعا وقراعة وكتابة، وتعليم اللغة من خلال الأنشطة اللغوية يتجه إلى تقديم الأنشطة و التدريبات للمتعلمين في أنماط مختلفة وكيفيات

(1) أعمال مؤتمر اتجاهات حديثة في تعليم العربية لغة ثانية، في التخطبط و التخطيط

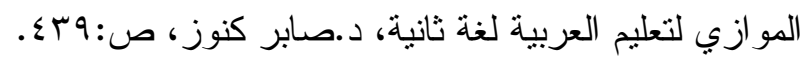

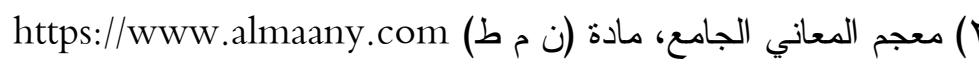




\section{أنماط الأنشطة اللغوية}

متعددة تساعد في تطوير الممارسة اللغوية لديهم بما يتتاسب مع احتباجاتهر و اختلاف مستوياتهم التعليمية (1). تصقل ممارسة الأنثطة اللغوية المهارات اللغوية للمتعلم، وتزيد معرفته

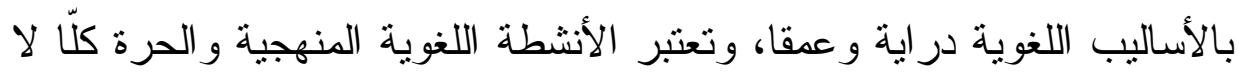

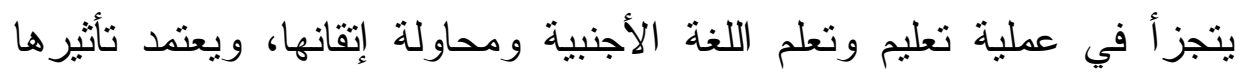

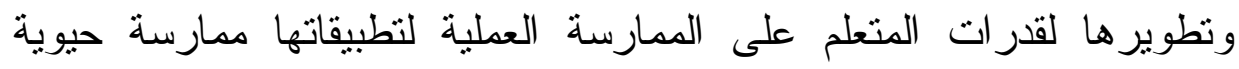

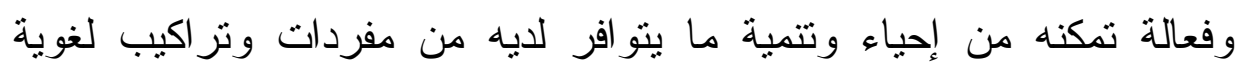

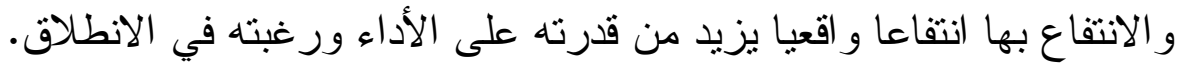

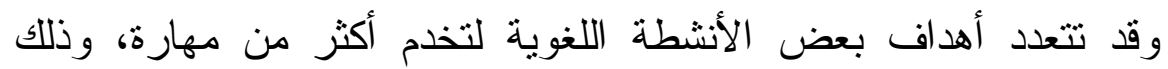

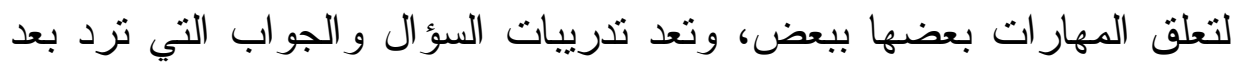

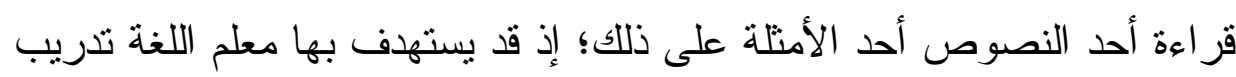

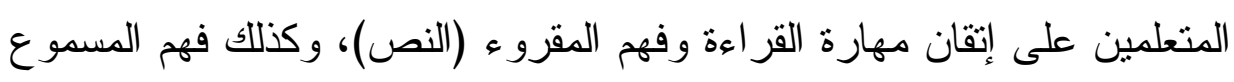
و إتقان مهارة التحدث بالإجابة.

أولا: أنماط الأنشطة اللغوية لمهارة الاستماع وتطبيقاتها:

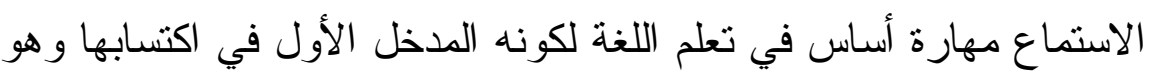

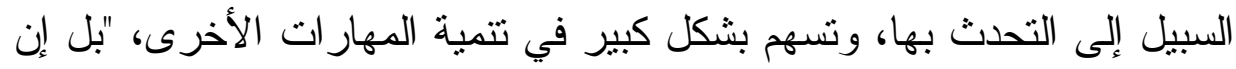

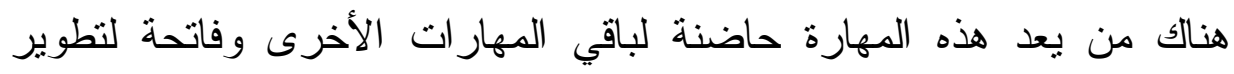

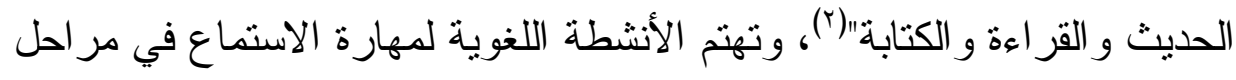

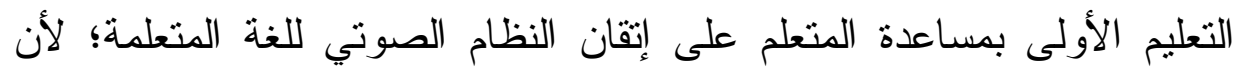

(1) أعمال مؤتنر اتجاهات حديثة في تعليم العربية لغة ثانية، الاتجاهات الحديثة في تعليم

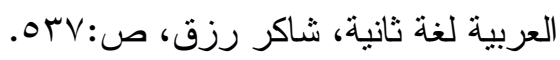

(r) ندريس اللغة العربية للناطقين بغيرها: مناهج تدريس الاستماع بين النظرية و التطبيق،

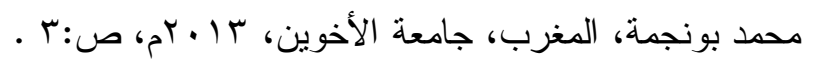




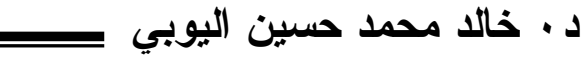

المتعلم ييقى قاصر ا عن أداء اللغة الثانية ما لم يحسن نطق أصواتها، وفي المر احل التالية تهنم الأنشطة اللغوية لمهارة الاستماع بتتمية قدرة المتعلم على

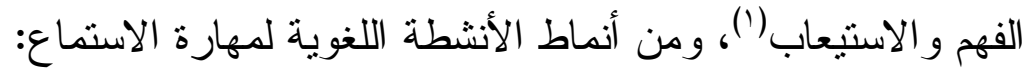
أ) أنشطة التعرف الصوتي:

تتتاول أنتطة التعرف الصوتي تعريف المتعلم بأصوات العربية وكيفية نطقها نطقا صحيحا مخرجا وصفة، وكذلك تعريفه بالحركات القصيرة و الطويلة و أهم الظواهر الصوتية المختلفة كالتتوين و التشديد(r)، وتقدم هذه الأنشطة في الأسابيع الأولى من مر احل تعلم اللغة ،وفيها يتم التركيز على الاستماع بكثرة إلى اللغة "التحصيل الألفة وتكوين ملكة التمييز بين اللغة الأم و اللغة الثانية"(")، وتعد تدريبات الترديد الجماعي والفردي من أبرز تدريبات التعرف الصوتي لأنه يهدف إلى تحقيق وتعزيز الاستماع و إنتاج ما يردد، كما يؤدي إلى تقويم الأداء النطقي لاى المتعلم، و لأن المتعلم في هذه الفترة لا يستطيع القراءة و الكتابة فإن تطبيقات أنشطة الاستماع ينبغي أن تر اعي اختلاف أنماط التعلم باستخلال الصور و الرسوم و الخر ائط و غير ها. ب) أنشطة الربط والتمييز الصوتي:

تهدف أنشطة الربط والتمييز الصوتي إلى الربط بين الصوت المسموع و الحرف المكتوب، و امتلاك القدرة على إدرالك الصوت وتمييزه عند سماعه

(1) مهار ات الاستماع اللازمة: مفهومها، أهميتها، أهداف تدريسها، أساليب تتميتها، علي

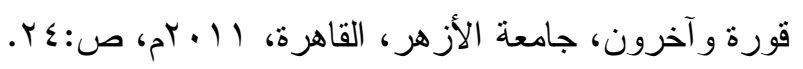
(Y) وثيقة بناء منهج تعليم اللغة العربية لغير الناطقين بها، إعداد قسم تعليم اللغة العربية

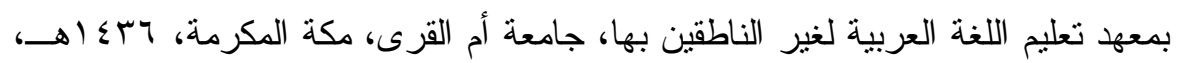
ص ص:0r-qם ب. (r) أعمال مؤتمر اتجاهات حديثة في تعليم العربية لغة ثانية، دور اللسانيات المعاصرة في

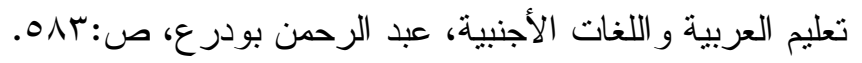




\section{أنماط الأشطة اللغوية}

منفصلا أو متصلا، وعلى التقريق بين الأصوات المتقاربة وتمييز كل واحد

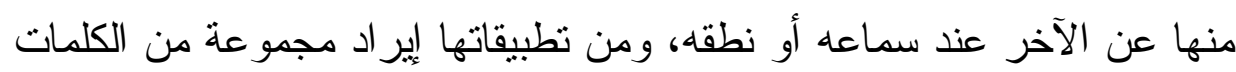

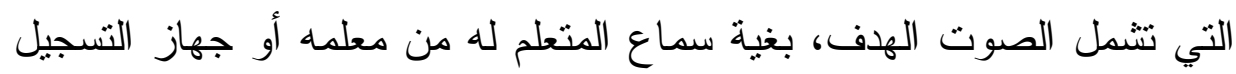

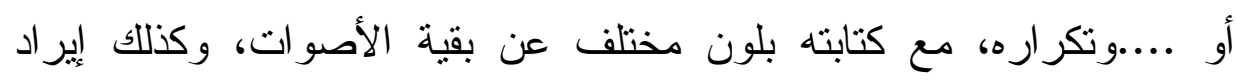

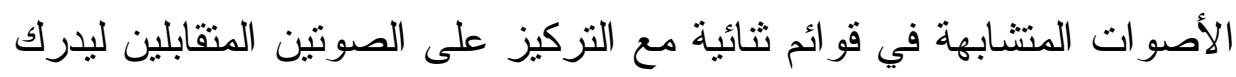

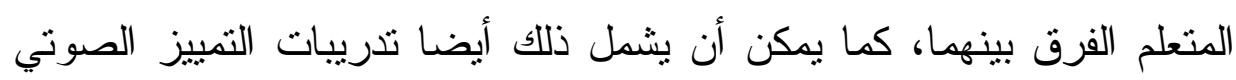
للكلمات و أوز انها.

\section{ج) أنشطة الإيقاع الصوتي: أنا.}

تهدف أنشطة الإيقاع الصوتي إلى تربية الأذن تربية سماعية من خلال

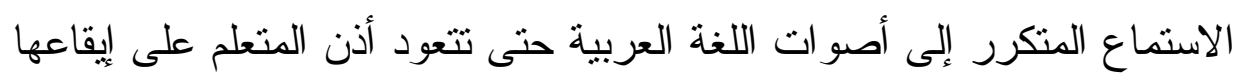

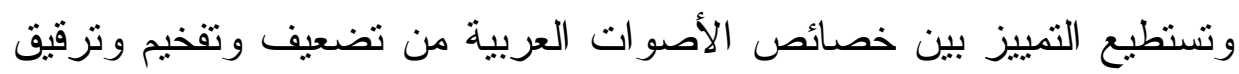

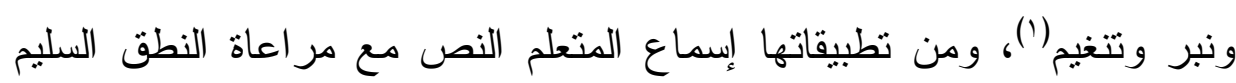
للغة و التفاعل مع المو اقف، وكذلك الاستماع إلى نصوص طبن طبيعية غير مقيدة

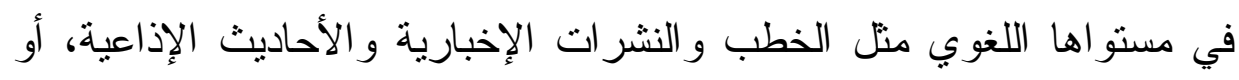

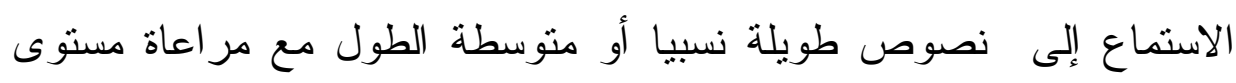
المتعلم.

\section{د) أنثطة (الفهم والاستيعاب:}

إن نمو المهارات اللغوية يقوم بالأساس على قدرة الفئعاب: لفرد على الاستماع

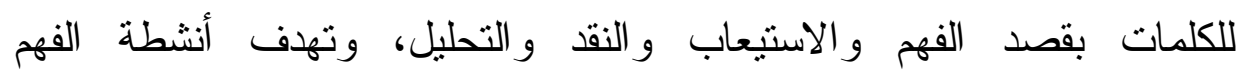

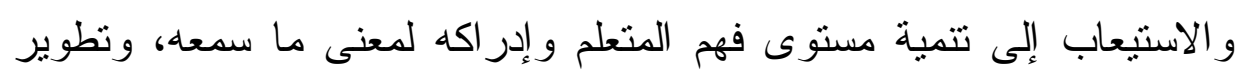

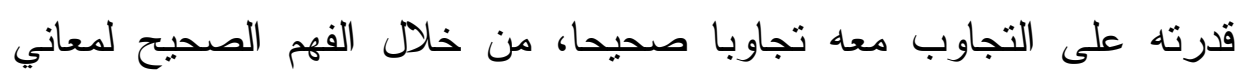

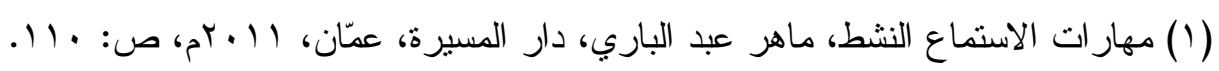




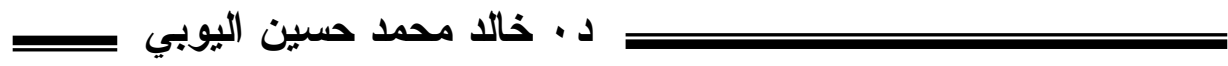
المفردات في السياق الذي ترد فيه، وتمبيز الأفكار الرئيسة عن الأفكار الثانوية، ومحاولة إيجاد رابط معنوي بين أجز اء النص المستمع إليه('). ومن أوجه التطبيقات التي تسهم في رفع مستوى الفهم والاستيعاب لدى المتعلمين: الاستماع إلى بعض التعليمات ومطالبتهم بتتفيذها، و الإجابة عن أسئلة شفوية مفتوحة ومتعددة عن المسموع، ومناقتنتهم فيما استمعوا إليه، وطلب إعادة سرد المسموع (كالقصة ونحوها) بعد سماعها من المعلم أو غيره. وينبغي أن ير اعى عند إعداد النصوص السماعية والتدريبات التدرج في وهي ذلك بما يناسب المستوى اللغوي الذي وصل إليه المتعلم أو الأعلى منه بقليل، كما ير اعى عند عرض المادة الصونية أن تكون نقية و اضحة الحروف صحيحة الضبط، مع العناية بمواضع الوقف و الوصل و النبر و التتغيم، و الابتعاد عن العموميات التي يمكن الجواب عنها بالخلفية التقافية لأنها لا تسهم في القياس الحقيقي لمدى تقدم المتعلم في مهارة فهم المسموع، كما أن من أبرز ما بطور فهم واستيعاب المتعلم سماعه للغة في مو اقفها الطبيعية منل تلقي الأوامر و إلقاء الأسئلة و وغير ها.

\section{ثانيا: أنماط الأشطة ولثيرة اللغوية لمهارة الكلام وتطبيقاتها:}

الكلام هو المظهر الو اقعي للغة الذي ينتج فيه المتكلم أفكاره، وهو الغاية

المنشودة من تعلم اللغات لأنه وسيلة الإفهام وأحد جانبي عملية التفاهم، ويمنل

- في الغالب- الجانب العملي التطبيقي لتعليم اللغة.(؟)

بيظر إلى تعليم التحدث على أنه جزء أساسي في منهج تعليم اللغة

الأجنبية، وتعد ممارسة الأنشطة الكلامية بمختلف أثنكالها وأوضاعها الممكنة

(1) تعليم اللغة اتصاليا بين المناهج و الاستر اتيجيات، رشدي طعيمة ومحمود الناقة، المنظمة

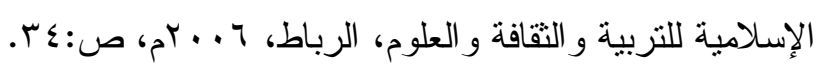

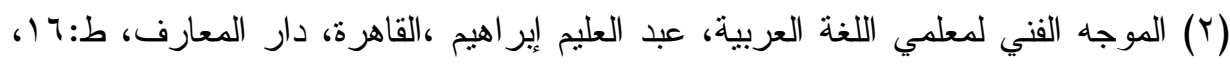


طريقة فعالة في تتمية وتفعيل العناصر اللغوية المكتسبة ، فهي تساعد على

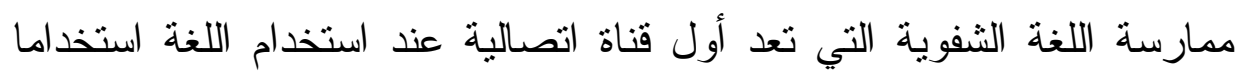
وظيفيا في مجالات التعبير الثفوي('). وتهدف الأنشطة اللغوية لمهارة الكلام إلى تتمية قدرة المتعلم على التحدث

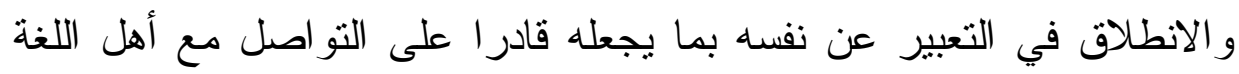

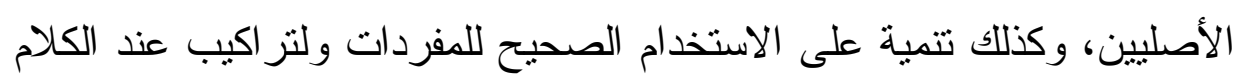
بما يمكنه من نقل أفكاره بشكل صحيح، إضافة إلى تتمية قدرته على النشاء إنشاء

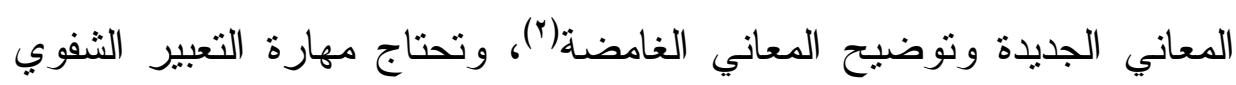
(الكلام) إلى التنريب على الكلام في ظروف مختلفة، ومن أنماط أنشطة مهارة

\section{أ) - (الإجابة عن الأسئلة:}

تدور أغلب تطبيقات مهارة الكلام في المستويات الأولى من تعليم اللغة الأبله:

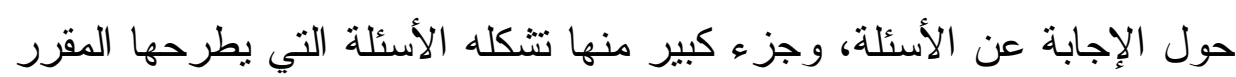
الدراسي أو المعلم ويقوم المتعلم بالإجابة عنها، وذللك كالإجابة عن أسئلة عامة الإنة

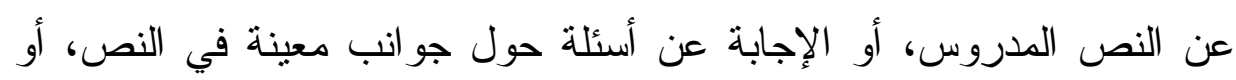

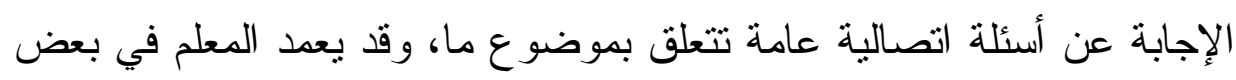

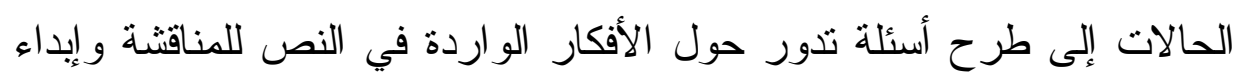

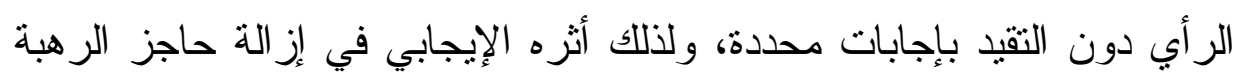
و الخوف عند المتعلم وإكسابه مزيدا من التقة في التحدث عن أفكاره("). (1) نظريات فسرت اكتساب اللغة، محمود عطية إسماعيل، جامعة المنوفية، مصر،

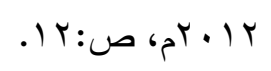

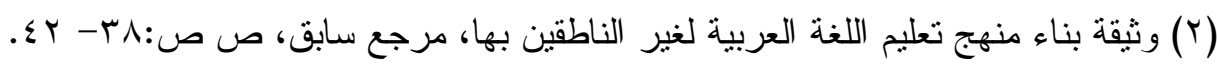

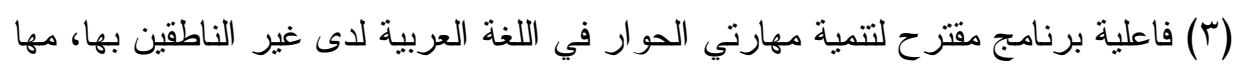

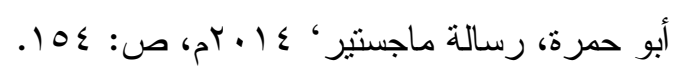


وقد لا يقتصر التطبيق في هذا المجال على تقديم الإجابة فقط، و إنما يدخل في ذلك تهيئة المتعلم لإعداد أسئلة لأجوبة مقترحة أو جديدة على غرار ما قام بالإجابة عن لتعويده على الممارسة الكلامية في الاتجاهين، وذلك كأن يطلب منه توجيه أسئلة عن النص المدروس، أو توجيه أسئلة حول جو انب معينة في النص ونحو ذلك، وقد بطلب في بعض التذريبات الجماعية بين المتعلمين تكوين الأسئلة و الأجوبة بشكل منداخل.

$$
\text { ب) الحوار: }
$$

الحوار من أكثر الأشكال الكلامية استخداما، وهو يسهم بشكل كبير في تطوير مهارة المحادثة لدى المتعلمين، وتتعكس آثار فاعلية مهارة المحادثة على لى المتعلمين في ممارستهم اللغة في مجمل عناصر ها ومكوناتها وكفاياتها. وللحوار أهمية كبيرة في تعليم اللغة، فهو غاية ووسيلة في الوقت نفسه، غاية لأنه الصورة المركزة لمحتويات الدرس التعليمي، و الأساس الذي يمد المتعلم بمختلف الجمل و التعبيرات و الألفاظ، وهو وسيلة لأنه يضم التز اكيب و المفردات في سياقات مختلفة تعتمد عليها التدريبات اللغوية التي يؤديها المتعلم ومن خلالها يستعمل اللغة تعبير ا واتصالا(')، ويتخذ نشاط الحوار تطبيقات عدة

- الحوار الثنائي، وفيه بطلب من المتعلم إجراء حوار مع زميله داخل الصف أو خارجه حول صورة تصف شيئا محددا أو مكانا ونحو ذلك. - تحويل الحوار النصي المقروء في الدرس إلى حوار شفهي و اقعي بين متحاورين أو أكثر من المتعلمين، و استبدال أسمائهم بأسماء شخصيات 
الحوار، و غالبا ما يشبه هذا الحوار الذي يدور بين مستعملي اللغة في الحياة

$$
\text { العامة. }
$$

- الحوار التعليمي، ويتم فيه اختيار عدد من الموضوعات التي تثير اهتمام المتعلمين وتلامس احتياجاتهم؛ وذللك لتحفيز هم على ممارسة الحديث حولها،

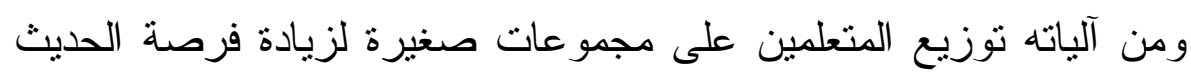

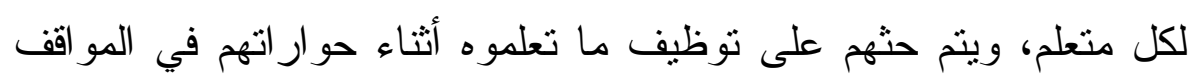

\section{الحقيقية.}

وقد يتخذ الحوار منحى التعليم من خلا أداء المتعلمين بعض الأدوار

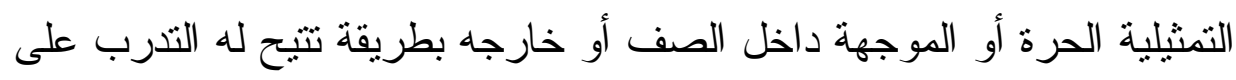

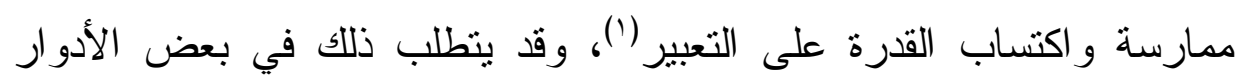
حفظ بعض النصوص النثرية أو الثعرية التي ترد في الدور الذي يقوم بتمثيله، وهو ما يكسبه بعض النز اكيب و الأنماط اللغوية التي ترنقي بمهارة الكلام لديه، ولهذا النوع من الحوار أنثره الإيجابي في زيادة ثقة المتعلم بنفسه وتطور أدائه

$$
\text { اللغوي (r) }
$$

- الحوار المسرحي، وهو حوار يؤدى على خشبة المسرح بطريقة تتيح للمتعلم

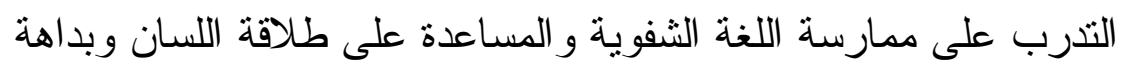

$$
\text { - التعبير }
$$

- المناظرة، وهي حوار يقوم على استعر اض وجهات النظر والآراء المختلفة حول موضوع معين ويكتسب منها المتعلم القدرة على التعبير عن الأفكار

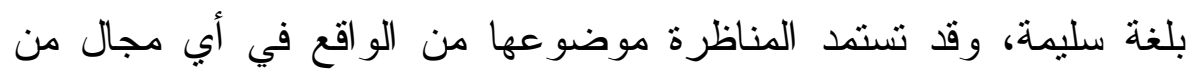

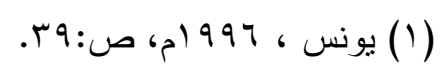

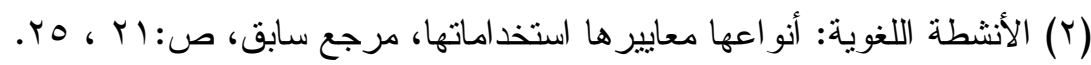




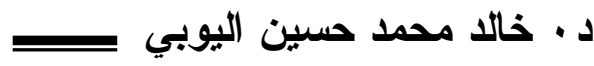

مجالات الحياة، أو من الخيال، "و اعتمادها في تعليم اللغة الثانية وتعلمها قد يفيد بانغماس المتعلم، نظر الاحتو اء المناظرة على تعبير ات لغوية و اقعية"(1). ج) المواقف التواصلية داخل الصف وخارجه: إن مشاركة المتعلم في مواقف تدفعه للتحدث باللغة تعد أحد أفضل الطرق لتطوير مهارة الكلام لديه، ومن وسائل تفعيلها تصميم مو اقف تعليمية تو اصلية تحاكي واقع المجتمع اللغوي، وتزداد فاعليتها في النشاط غير الصفي لأنها تكون فيه أقرب إلى الو اقعية بيئة وظروفا؟)، ومن تطبيقاتها: قيام المتعلم بإلقاء وناء كلمة قصيرة أمام زملائه، أو إدارته حوار ا قصير ا مع أحد الناطقين الأصليين. د) التعبير الشفوي: التعبير الثفوي هو إظهار الفرد لأفكاره ومشاعره ونقلها إلى الآخرين بواسطة الكلام، وتهدف أنشطته اللغوية إلى تمكين المتعلم من التعبير عن نفسه بلغة سليمة، و استعمال ما تعلمه في مو اقف طبيعية مختلفة، ومن تطبيقاته: إتاحة الفرصة للمتعلم للتحدث الحر في فكرة تتصل بما درس، ووصف المحتوى الذي هو تدل عليه الصورة، و التحدث عن كيفية التصرف في مواقف افتر اضية، و إجر اء مقابلات مع أهل اللغة الأصليين، و الألعاب اللغوية الثفهية. ثالثا: أنماط الأشطة اللغوية لمهارة القر اعة وتطبيقاتها:

مهارة القراءة من المهار ات الأساسية في تعلم أي لغة، وهي أداة المتعلم التي تمكنه من الاستمرار في التعلم والاتصال بالإنتاج الفكري والأدبي و الحضاري لأصحاب اللغة المتعلمة، وتسهم الأنشطة القر ائية في زيادة المعجم اللغوي للمتعلم وتتمية مداركه، وتهدف إلى تتمية قدرته على القر اعة الصحيحة، (1) فاعلية برنامج مقترح لتتمية مهارتي الحوار في اللغة العربية لاى غير الناطقين بها،

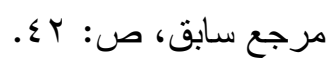

(Y) اتجاهات حديثة في تدريس اللغة العربية، طه الدليمي وسعاد الوائلي، جدارا للكتاب

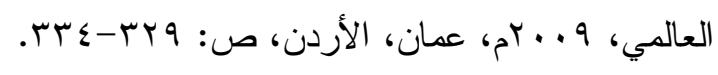




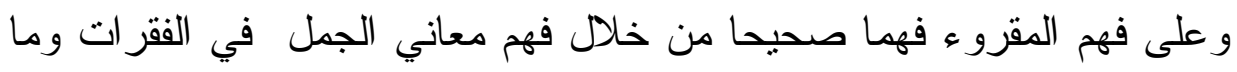

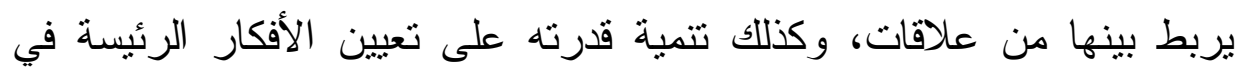

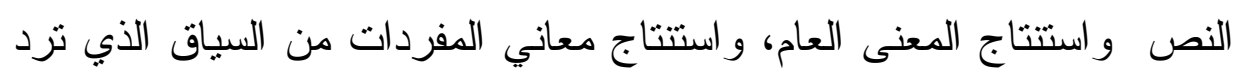
فيه (')

وينبخي أن تقدم القراءة للمتعلم المبتدئ بشكل مندرج انطلاقا من الكلمة

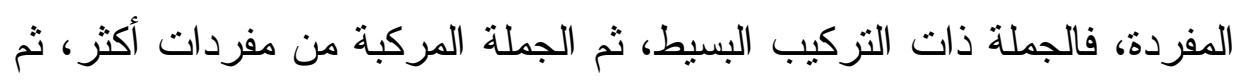
يقر أ المتعلم الفقرة التي تتألف من بعض الجمل المتحدة في سياقها، وبعدها ينتقل إلى النص الطويل المكون من عدة فقرات تتنظم تحت عنو ان واحد وتتناول كل واحدة منها فكرة جزئية، ومن أنماط أنشطة مهارة القر اعة:

$$
\text { أ ) التعرف على القراعة: }
$$

وهي الأنشطة الأولية التي تقدم للمتعلم لاكتساب مهارة القراءة، حيث

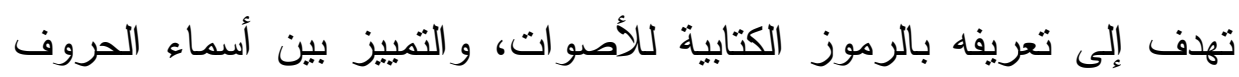

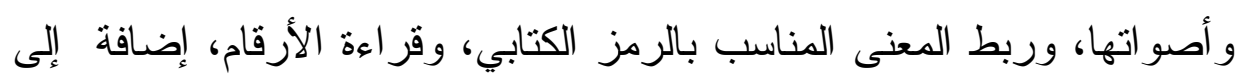

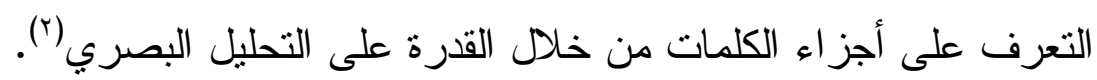

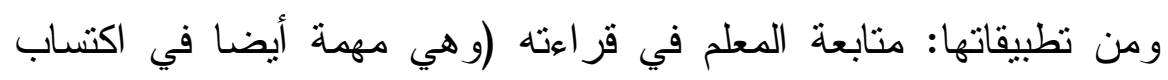

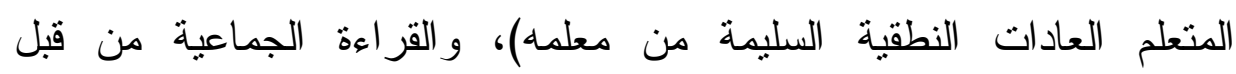
المتعلمين، وحفظ الجمل الحوارية البسيطة ثم قر اعتها. ت) التعرف على معاني المفردات: المفردات اللغوية هي اللبنات الأساسية لأية لغة، وهي الأداة التي يستطيع

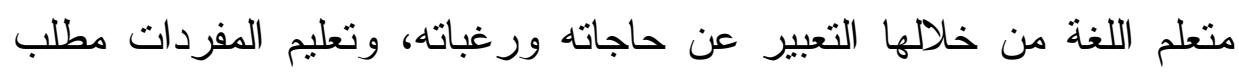
مهم لاكتساب اللغة، ولذا تهاف أنشطة المفردات اللغوية إلى تعريف المتعلم

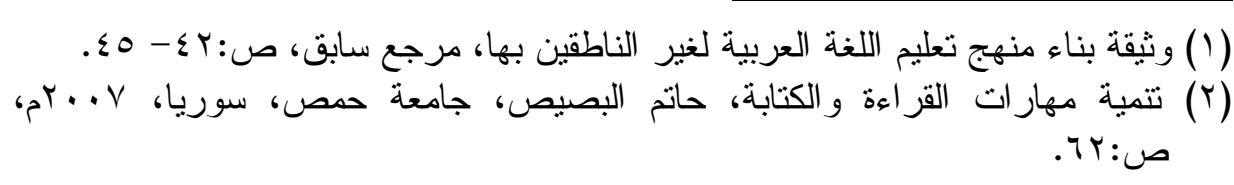


د · خالد محمد حسين اليوبي سب

كيفية قر اعة المفردات اللغوية ومعرفة معانيها المعجمية و استخداماتها، و إكسابهوخاصة في المستويات الأولية -المفردات المتعلقة بالجانب التواصلي لمساعدته على أداء الوظائف اللغوية المطلوبة في الموقف الاتصالي، ولذلك أثزه النفسي البالغ على متعلم اللغة والذي بتمنل في انفتاحه على أهل اللغة المتعلمة وشعوره بالر احة عند التعامل معهم ('). وينبغي - مع مر اعاة مناسبة المفردات لمستوى المتعلم - أن يتم التركيز في أنشطة المفردات اللغوية على المفردات التي تتوافر فيها الخصائص مرس التالية)(ب) - الثيوع، وهي المفردات التي يكثر استعمالها ولها انتشار و اسع عند أهل اللغة.

- السهولة في النطق بالنظر إلى مخارج حروفها. - العموم، وهي المفردات التي يستخدمها الفرد عادة في حياته اليومية ولا تتحصر في مجال بعينه.

- الاتساع الجغرافي، حيث تقدم الكلمة التي تستعمل في جميع البلاد العربية على غير ها.

- الأهمية، وهي المفردات التي تتطلبها الحاجة في المو اقف الحياتية المختلفة. ومن تطبيقات أنشطة التعرف على معاني المفردات: معرفة المعنى المعجمي للمفردة، ومعرفة النكرة و المعرفة، و المذكر و المؤنث، و المفرد وكيفية

(1) تعليم المفردات اللغوية، ماهر شعبان عبد الباري، دار المسيرة للنشر والنوزيع

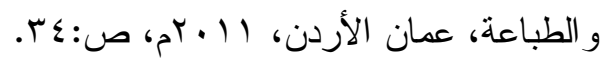

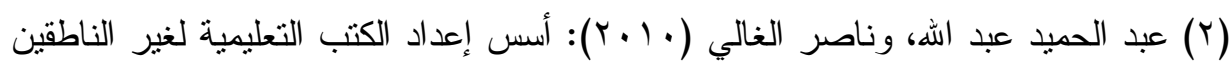

$$
\text { بالعربية، القاهرة، دار الاعتصام، ص: •^. }
$$

و "تطوير مناهج تعليم اللغة، جالك ريتشاردز، ترجمة ناصر غالي وصالح الثويرخ،

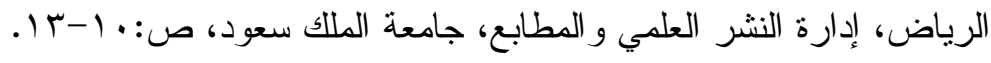


تثنيته وجمعه، ومعرفة الكلمات التي لها الدلالة نفسها (المتر ادفة)، و الكلمات

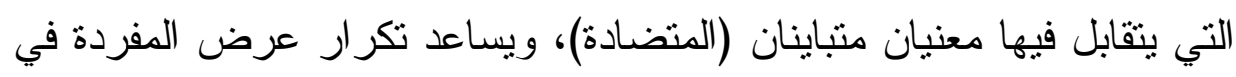

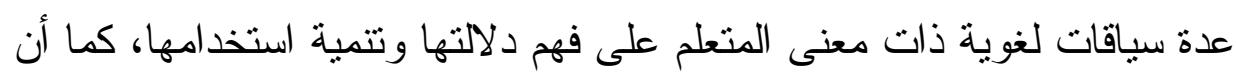
التعرف على معاني بعض المفردات اللغوية قد ينت بطرق أخرى غير كتابية،

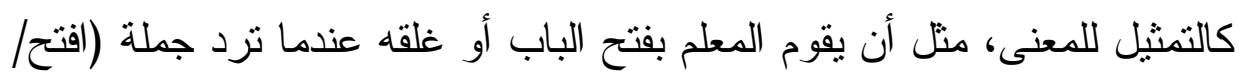

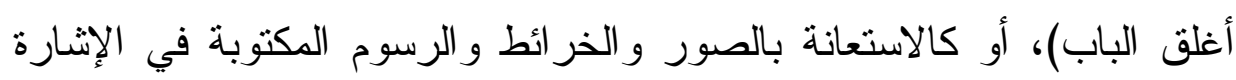

$$
\text { ج) }
$$

ينتقل متعلم اللغة بعد تعرفه على مهارة القراءة إلى مرحلة فهم المقروء،

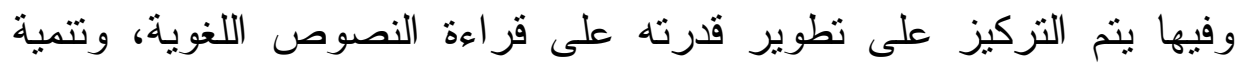

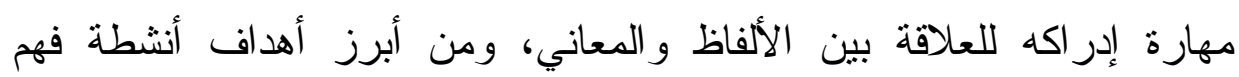

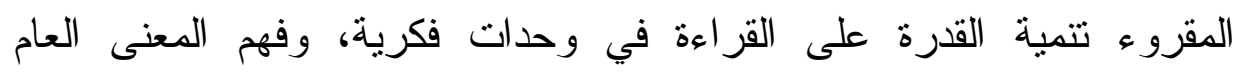

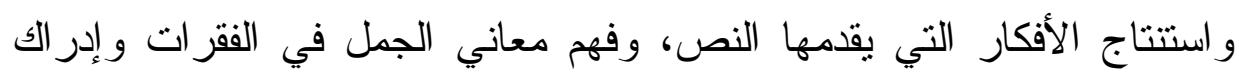
علاقات المعنى التي تربط بينها، و استتناج معاني المفردات من السياق الذي نرد فيه، ومن أبرز تطبيقاتها: - القراءة الصامتة حيث يستخدم فيها المتعلم بصره لمطالعة النص وتكوين تصور مبدئي يساعد على معرفة دلالته.

- قر اهة نصوص حوارية وقصصية طريفة ذات جمل قصيرة.

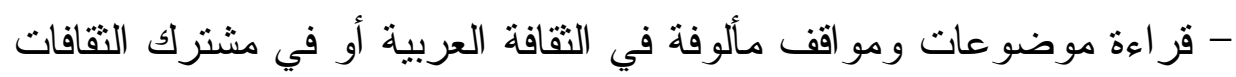
العالمية.

وتعتبر القصة وسيلة مهمة لتتمية مهارة القراءة والفهم لاى متعلم اللغة الثانية، فهي تثزي حصيلته اللغوية وتقوي قدرته على التحدث، وتطور ملكته

$$
\begin{aligned}
& \text { (1) تعليم الدفردات اللغوية، مرجع سابق، ص: 90ب، ؟ ؟ـ. } \\
& -1 \text { r人 }
\end{aligned}
$$




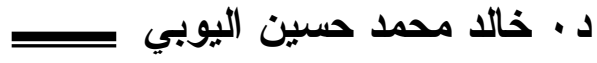

التعبيرية، كما أنها تطور قدرته على فهر المضمون وتعرفه على الطرق المختلفة لبناء النص وعرض الأفكار وربطها'(1). د) الاستيعاب القرائي:

ويقصد به العمل على تطوير قدرة المتعلم ورفع مستوى فهمه و استيعابه لما يقرؤه، و استخر اج المعنى من خلال المعلومات الواضحة التي يعرضها النص، أو من خلال المعلومات الضمنية فيه، أو من خلا لم المعرفة و الخبرة السابقة(؟)، وتهدف أنشطته اللغوية إلى تجويد الانطلاق في القراعة مع السرعة و الدقة و الفهم، وتحسين مهارة القر اعة الجهرية، و تقديم أداء صوتي سليم ومعبر يعين على استتباط المعنى وفهم العبار ات، و إثراء قاموس المفردات وترسيخ قو اعد اللغة وبنية النص اللغوي، وفهم الأفكار الجزئية والتفاصيل و إدر الك العلاقات بين الأفكار، ومن أبرز تطبيقات الاستيعاب القرائي: قراءة نصوص وله وله طويلة نسبيا، ومناقثنة المحتوى ونقده، وتمبيز المعنى المباثر للنص و المعنى

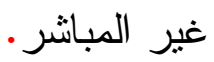

رابعا: أنماط الأشطة اللغوية لمهارة الكتابة وتطبيقاتها:

الكتابة إحدى وسائل الاتصال اللغوي، وهي ضرورة اجتماعية لمتعلم اللغة

لنقل أفكاره و الوقوف على أفكار الآخرين، و إليها يستتد في بعض المواقف الاتصالية مع الآخرين بالتعبير عن نفسه وفكره كتابيا، وتنهم ممارسة الأنشطة الكتابية في إحياء وتتمية الألفاظ و التزراكيب اللغوية لدى المتعلم، وتمكنه من إطلاق العنان لخياله وفكره(r).

(1) أعمال مؤتمر اتجاهات حديثة في تعليم العربية لغة ثانية، دور القصة القصيرة في تعليم اللغة العربية لغة ثانية ،فاطمة الكحلاني، ص:ب ـ T.

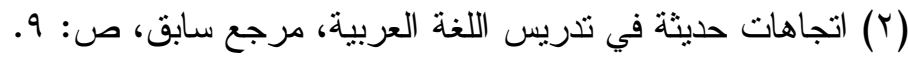
(T) طرق تدريس اللغة العربية، إبراهيم زكريا، دار المعرفة الجامعية، الإسكندرية، 11:ص ص م 1999 


\section{أنماط الأشطة اللغوية}

تهدف الأنشطة اللغوية لمهارة الكتابة إلى تعريف المتعلم كيفية كتابة الحروف العربية و إدر الك العلاقة بين شكل الحروف و أصو اتها، وكيفية كتابة الكلمات العربية مع تمييز كيفية كتابة الحرف في أول الكلمة ووسطها و آخر ها، و إتقان طريقة كتابة الحرف العربي (الخط العربي)، و الكتابة السليمة الواضحة و المعبرة بتطبيق مبادئ الإملاء العربي و إدر الك أهم ما فيه من الاختلافات بين

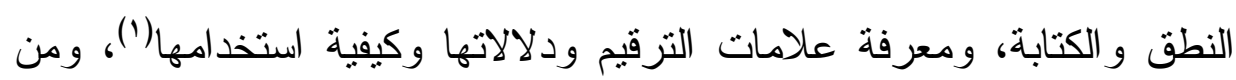
أنماط أنشطة مهارة الكتابة: أ) رسم الحروف الهجائية:

ومن تطبيقاته: نسخ الحروف الهجائية في أثكالها المختلفة ومو اضعها في الكلمة، وكتابة الكلمات العربية بحروف منفصلة وحروف متصلة؛ مع تمييز أثكال الحروف ومر اعاة التتاسب بين الحروف طو لا و اتساعا؛ وتتاسق الكلمات في أوضاعها و أبعادها، ويلحق بالرسم معرفة كيفية وضع الحركات القصيرة و علامات المد والثدة والتتوين على الحروف، والتعود على نظام الكتابة العربية من اليمين إلى اليسار • ب) الكتابة الإملانية:

تهدف أنشطة الكتابة الإملائية إلى معرفة القواعد الأساسية في الإملاء و الهجاء العربي، وتتمية قرة المتعلم على الكتابة الصحيحة إملائيا للكلمات و الجمل و الفقرات و النصوص، ومن تطبيقاتها التذريب على أهم أسس وقو اعد

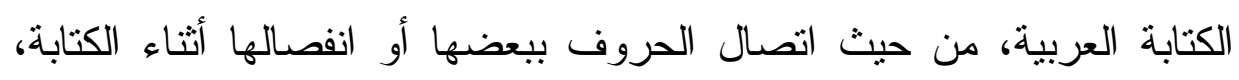
وكيفية كتابة الههزة و (ال) التعريف الثمسية والقمرية، و التاء المفتوحة و المربوطة....... مع توضيح أهم ما يكتب خلاف القاعدة كالحروف التي تتطق

(1) وثيقة بناء منهج تعليم اللغة العربية لغير الناطقين بها، مرجع سابق، ص:0 ـ - ^؟ 
د · خالد محمد حسين اليوبي لـ

و لا تكتب (هذا)، و الحروف التي تكتب ولا تتطق(قالوا)، ويتتقل المتعلم في التذرب على الكتابة الإملائية ما بين الإملاء المنقول والمنظور و الاختباري • ج) القواعد النحوية:

اللغة نظام من القو اعد اللغوية التي تحكمها، و القو اعد النحوية أحد مكونات هذا النظام، ويعد تدريسها المكون الأساسي الأول في تعليم اللغة الأجنبية بطريقة النحو والترجمة، ولها أهميتها كذلك في طرق التعليم الأخرى؛ فتمثل أحد الأسس في الطريقة السمعية الثفوية ولكن تؤخر إلى ما بعد المستوى الأول، وتكتسب في الطريقة المباشرة بالمران على استخدام اللغة في مواقف

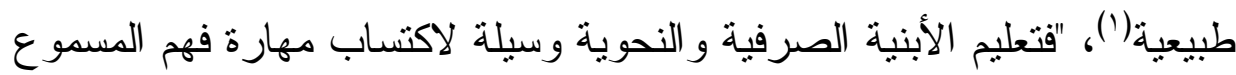
و المقروء و إفهام الآخرين ونقل الأفكار إليهم بالتعبير الثفهي و التعبير الكتابي"(؟)، وتبرز أهمية القو اعد النحوية في أنها القانون الذي يوجه مسار الأداء اللغوي شفهيا أو تحريريا، وهي في التطبيقات الكتابية لأنها قوام مهارة الكتابة؛ إذ لا تتم مهارة الكتابة دون معرفتها وتمثلها في المكتوب. تهدف أنشطة القو اعد النحوية إلى تمكين المتعلم من فهم قو اعد اللغة و استعمالها المناسب في سياقاتها المختلفة، وصو لا إلى تحقيق التو اصل و التفاعل مع أبناء اللغة المتعلمة، وفيها يتم العمل على تقديم القو اعد الأساسية والأكثر

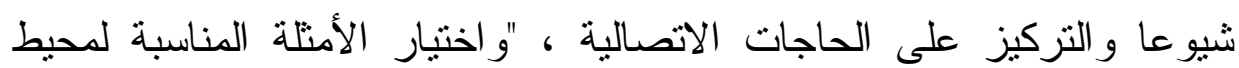

(1) المهار ات اللغوية: مستوياتها، تدريسها، صعوباتها، رشدي طعيمة، دار الفكر العربي،

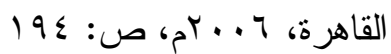
(r) عبدالل، رحمت، الأنماط اللغوية في تعليم اللغة العربية للناطقين بغيرها، الجامعة

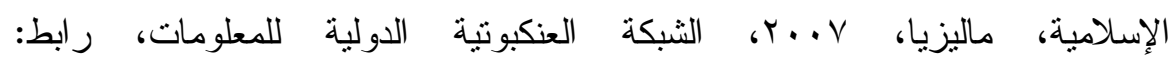
irep.iium.edu.my//94/7 
المتعلم حتى تبدو لديه كنصوص حقيقية يدرك قيمها ومعانيها ويتفاعل معها بما

يستثير فيه ملكة اللغة"(1).

وينبغي أن ير اعى في تقديم أنشطة القواعد و التر اكيب أن المتعلم يتعلمها في بيئة تعليمية بشكل مقصود خلافا لما هو عليه حال الناطق الأصلي للغة فئة حيث يكتسبها في بيئة طبيعية بشكل غير مقصود، كما ينبغي أن نكون المادة

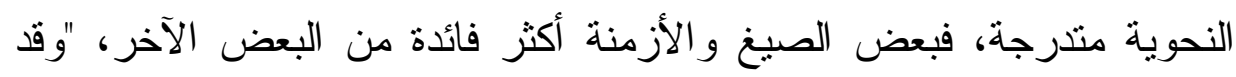
نجد في غالبية اللغات قوانين أساسية معينة في القواعد و النحو و التي يعتمد

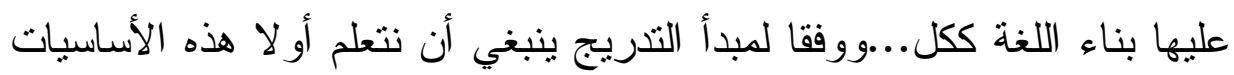

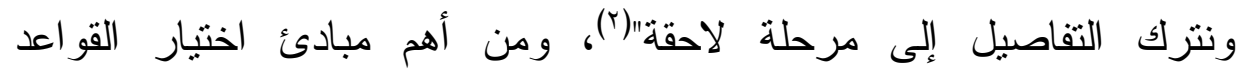
و التز اكيب التعليمية لمتعلمي اللغة (r): - التتاسبية لمستوى المتعلم وتقديم ما يمكن تعلمه على ما ينبغي تعليمه.

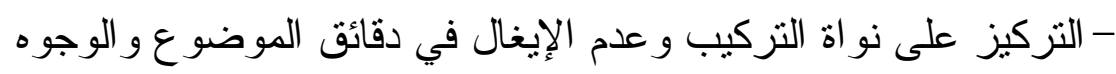
المتعددة له و الثو اذ عن القاعدة.

- الاكتفاء بتركيب و احد من التز اكيب التي تؤدي نفس المعنى. - التدرج في تقديم التر اكيب من الأسهل إلى الأصعب.

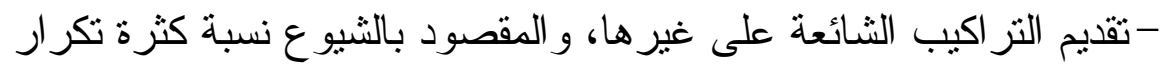
استخدام موضو ع النحو في لغة الكتابة و الحديث. - الوضوح و السهولة في صياغة المعلومات من حيث طريقة العرض و الأمتلة

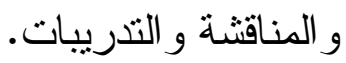

ا أعمال مؤتمر اتجاهات حديثة في تعليم العربية لغة ثانية، لسانيات التلفظ وتعليم العربية

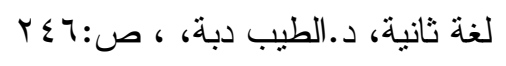

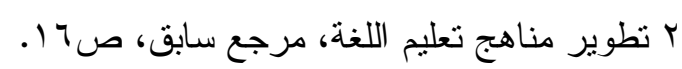

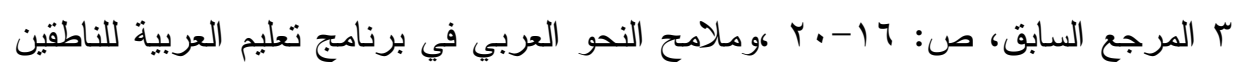

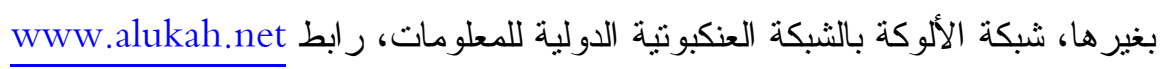




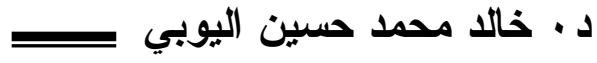

ومن أهم تطبيقات أنشطة القو اعد و التراكيب في المستويات الأولى (') الفعل الماضي و المضار ع و الأمر، الاسم المفرد و المثتى و الجمع، الاسم المعرفة

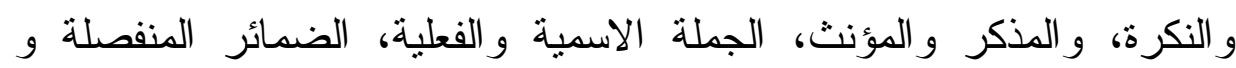
المتصلة، أسماء الإشارة و الأسماء الموصولة، ظروف وله الزمان و المكان، أدوات الاستقهام وحروف الجواب، نفي الأسماء و الأفعال، وتطبيقات أنشطة القو اعد و التز اكيب وتدريباتها تتعدد وتتتوع بتعدد أبواب وموضوعات نحو العربية وصرفها(؟)، و اقتصرت فيما سبق على ما يمكن أن يعد من قبيل الأساس للمتعلم المبتدئ، ولتثبيت القو اعد و التركيب فإن تدريباتها المرتبطة بهه تجرى - غالبا - شفهيا أو لا، ثم قر اعة وكتابة، وتتدرج حسب المستويات اللغوية للمتعلمين، وينبغي أن يراعى في تعليم القواعد النحوية أن تكون الأمنلة التوضيحية للاروس مناسبة وغير معزولة عن سياقها. ومع أن لتدريبات أنشطة القو اعد والتزاكيب تعلقا بالمعنى فإنها تنعدد لتشمل التدريبات الآلية (الأنماط اللغوية) وخاصة في المستويات الأولية، وقد يؤدي المتعلم بعض التدريبات دون معرفة معاني مفردات التركيب، وخاصة في المر احل الأولى من تعليم اللغة، سعيا إلى سيطرة المتعلم على النمط التركيبي بشكل تلقائي اعتمادا على القياس، ويتم تدعيم الاستجابات الصحيحة من خلا اله

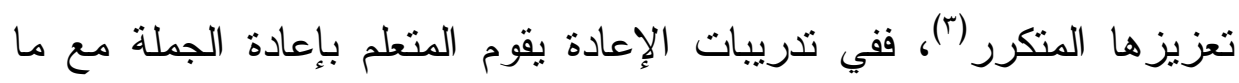
يحصل فيها من تغيير دون أن يستلزم ذلك منه فهم محتو اها ، ومثنال ذلك إعادة

(1) ينظر: المهار ات اللغوية: مستوياتها، تدريسها، صعوباتها، مرجع سابق، ص:^ه وما

$$
\text { بعدها. }
$$

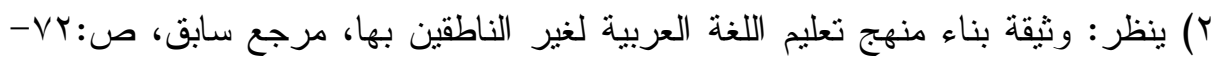

( $५$ ) McDonough, Steven. H.(। १९५) : Psychology in foreign language teaching.

London : George Aiien and Unwinhtd. P: 9 


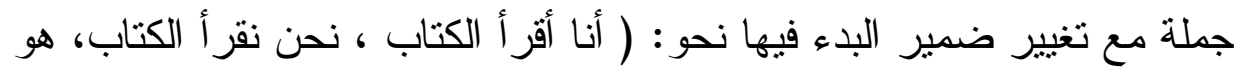

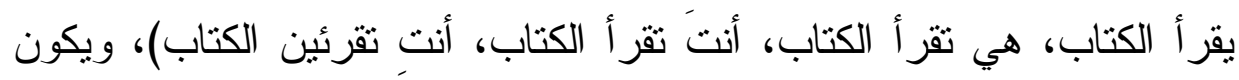

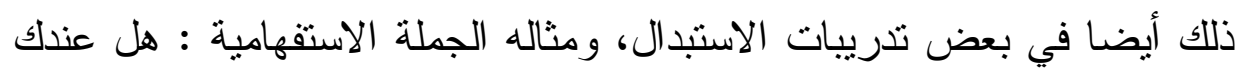

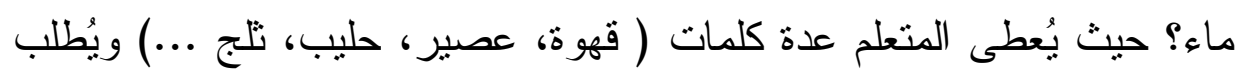

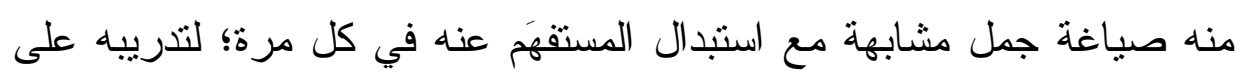
كيفية صياغة أسلوب الاستقهام (1).

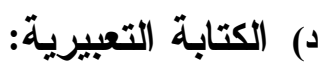

تهدف أنشطة الكتابة التعبيرية إلى تتمية قدرة المتعلم للتعبير عمّا لديه من

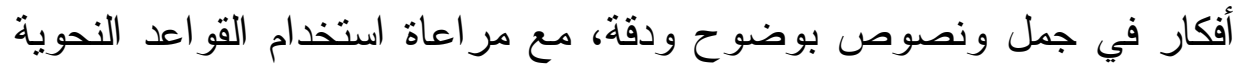
و الأسلوب المناسب للموضوع أو الفكرة المعبر عنها، ويندرج المتعلم في الكتابة التعبيرية من المستوى البسيط إلى الكتابة الموجهة إلى الكتابة الحرة، ومن ولنئ

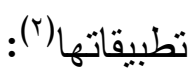

- تلخيص النصوص المقروءة تلخيصا كتابيا و افيا، تلخيص فقرة أو حدث أو مشهد.

- كتابة خطاب ذي هدف محدد مع استيفاء عناصر الخطاب، كتابة تقرير حول مشكلة أو قضية ما.

- إعادة صياغة النص مع الاستعانة بكلمات مساعدة. - تحليل فقرة أو نص ، التعليق على صورة أو فكرة أو مشهد.

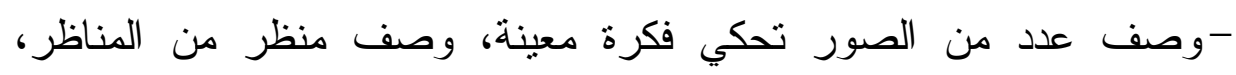
وصف أحداث معينة، وصف مقابلة.

(1) ينظر : تعليم اللغة العربية لغير الناطقين بها في ضوء المناهج الحديثة، د.مختار الطاهر

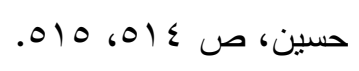

(r) مجلة جامعة الملك عبد العزيز : الآداب والعلوم الإنسانية، فاعلية الأنشطة غير الصفية

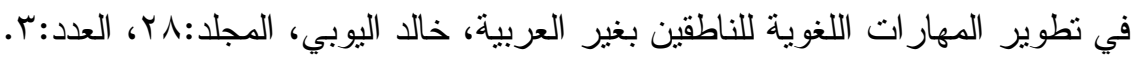


-صياغة الإعلانات و اللافتات.

-ملء النماذج و الأور اق الرسمية (طلب خدمة، منحة در اسية...)

وير اعي في تدريبات مهارة الكتابة التعبيرية "التذرج في الكتابة من الجملة

إلى الفقرة إلى النص بحسب المستوى اللغوي للدارسين، فيمكن البدء بالتدريبات الكتابية التي تزكز على الجملة منتل: الإجابة عن أسئلة حول مضمون النص أو إنى وصف شخصيات أو أمكنة، أو إعادة صياغة بعض الجمل المقتطعة من النص، أو إكمال بعضها الآخر، أو إعادة صباغة مقولة لبعض الشخصيات ، أو صياغة الأفكار الرئيسة في عدة جمل، أو كتابة جملة تلخص رسالة الكاتب، أو إعادة كتابة بعض التز اكيب بطرق مختلفة"(1).

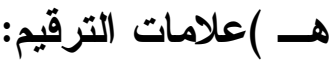

علامات التزقيم رموز شكلية عرفية تستععل في النصوص المكتوبة، وتؤدي وظائف مهمة في بنية النص ومضامينه، وتهدف أنشطة علامات الترقيم إلى تعريف متعلم اللغة هذه العلامات وما تدل عليه في سياق النص وكيفية استخدامها، ومن تطبيقاتها: - الدلالة على مضمون الأسلوب اللغوي كما في التعجب و الاستقهام و غير هما. - الإشارة إلى نص المقول، وتمييز المنقول من خارج النص. - تقسير المضمون وترتيبه وبيان أقتسامه. الأشطة اللغوية وأنماط التعلم:

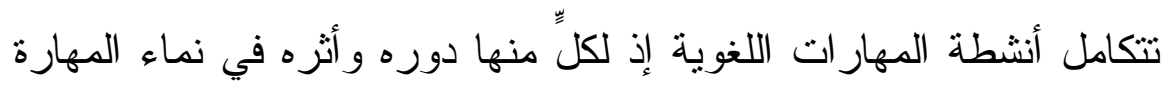
اللغوية لاى المتعلم، ويقوم معلم اللغة باختيار المناسب منها في أنماطها

(1) دور القصة القصيرة في تعليم اللغة العربية لغة ثانية، فاطمة الكحلاني، أعمال مؤتمر

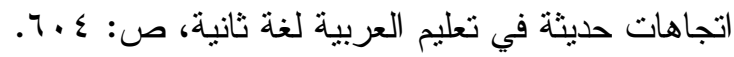




\section{أنماط الأشطة اللغوية}

وتطبيقاتها المختلفة، والمزاوجة بين تدريباتها بما يناسب مستويات المتعلمين ويحقق أهداف المنهج التعليمي. ولهي.

ومما يزيد فاعلية الأنثطة اللغوية المنهجية وغير المنهجية في مجال تعليم

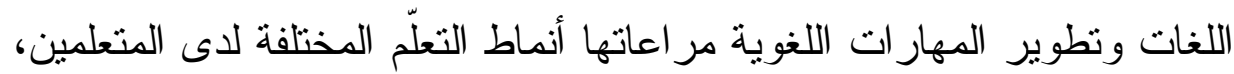
و النمط التعلّمي هو الأسلوب أو المنحى الفردي الذي يفضله المتعلم لتأدية

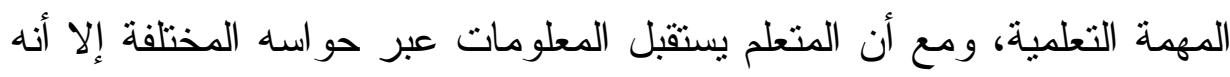
يتقاعل مع إحدى حو اسه بشكل أكبر من الحواس الأخرى ('). إن نمط التعلم ليس ما يتعلمه الفرد ولكنه كيف يتعلم، وتصنف الأنماط

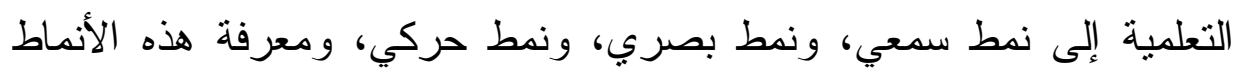
التعلمية المختلفة تساعد المعلم على تمييز استجابات المتعلمين وقياس مدى

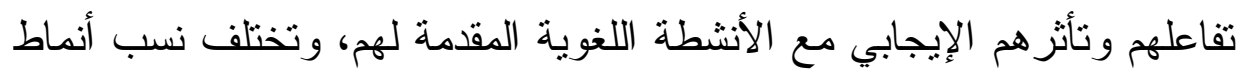

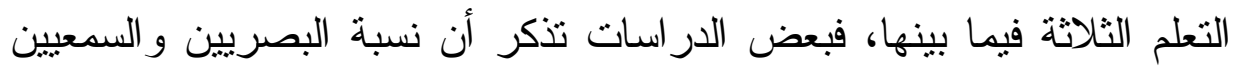

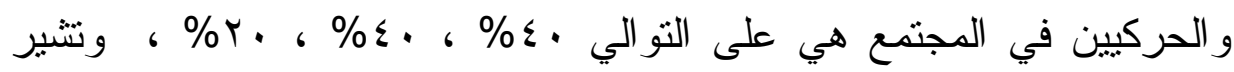

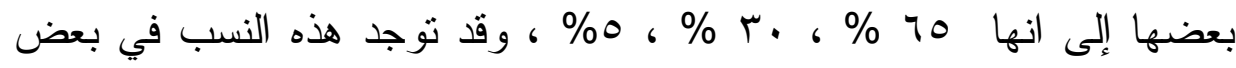

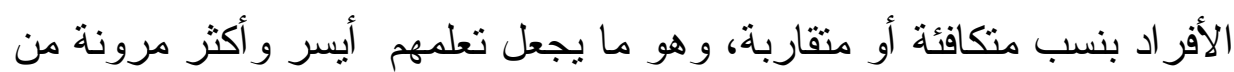
غير هم (r). تختلف خصائص البصريين و السمعيين و الحركيين عن بعضهم البعض،

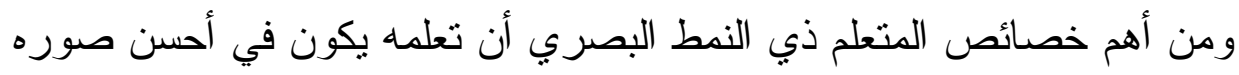

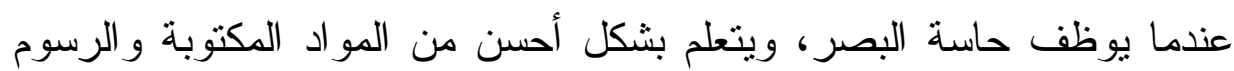

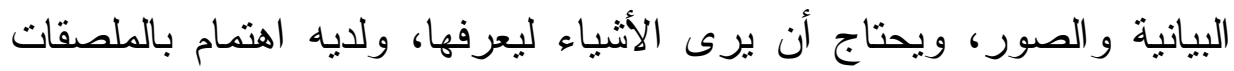

(1) الابتكار في اللغة العربية بين التربية والتعليم والتعلم، أنور طاهر رضا، دار غيداء

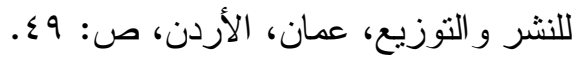

$$
\begin{aligned}
& \text { (Y) المرجع السابق، ص: .0. }
\end{aligned}
$$




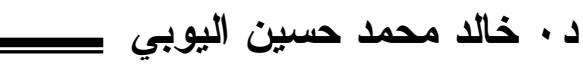

الحائطية و الألوان، ويفضل التعليمات المكتوبة، ويفضل أن يرافق الحديث عن الأثياء صور وأثنكال توضيحية، ويستمتع بالأنثطة و العروض البصرية ومشاهدة الأفلام التعليمية، ويواجه صعوبة في تتبع التوجيهات اللفظية، ولا يتحمل المواقف التي تتطلب الاستماع لفترة طويلة(')، وتفيد الوسائل التعليمية التي تخاطب العين المتعلم البصري ويتعلم من خلالها بشكل أفضل، وذلك من منل الصور الفوتوغر افية و الصور التوضيحية و الرسوم البيانية و الثرائح و الثفاقيات و الجداول و الأثكال و الخطوط و الكاريكاتير ات و الخر ائط المسطحة

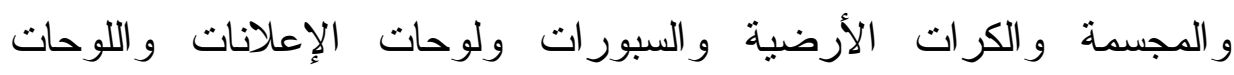

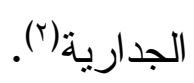

و أما المتعلم ذو النمط السمعي فإن تعلمه يكون في أفضل صوره عندما يوظف حاسة السمع، ويتعلم بالحديث أكثر من الوسائل الأخرى من بصرية أو حركية، ويفضل التعليمات اللفظية ويتذكر ما بسمع، ويسأل أسئلة كثيرة لفهم و إدر الك كنه الأثياء، ويفضل الاستماع على القراءة ويتعلم من خلال الاستماع لمناقثة موضوع ما، ويتذكر نسبة كبيرة من المعلومات التي يسمعها، ولديه القدرة على ملاحظة الفروقات الصوتية، ويرتاح للمعلومات التي تز افقها مؤثر ات صونية، ويجد صعوبة في اتباع التعليمات الكتابية(ץ). ومن خصائص المتعلم ذي النمط الحركي أن تعلمه يكون في أفضل صوره عندما يفعل الأثياء بيديه، ويستمتع بالدروس التي تتضمن أنشطة عملية، وبممارسة الأنشطة البدنية، ويتعلم بشكل أفضل عندما يستخدم جسمه ككل وليس يديه فقط (تمثيل مسرحية، قصة حركية ...)، ويتذكر الأشياء التي فعلها

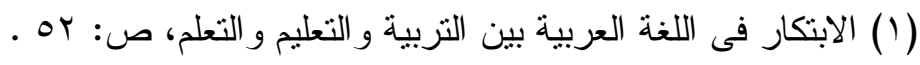

$$
\begin{aligned}
& \text { بالمرجع السابق، ص: }
\end{aligned}
$$

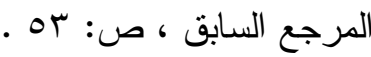


وجربها عمليا في الماضي، ويفضل الاكتثاف بالتجربة على التعليمات

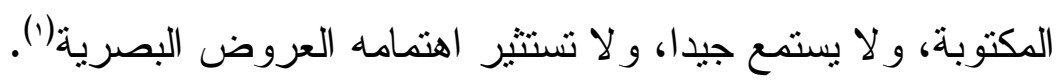

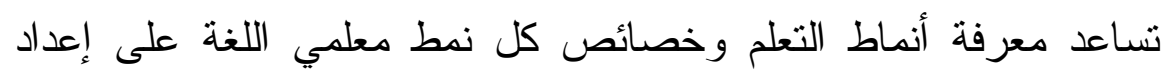

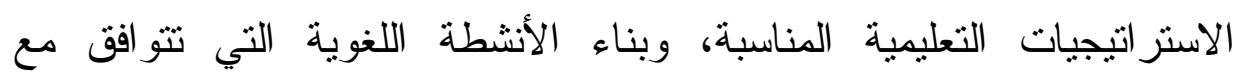

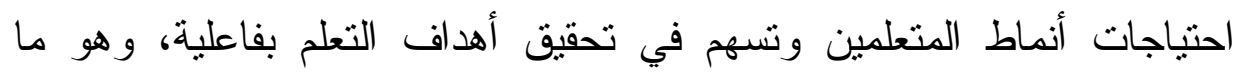

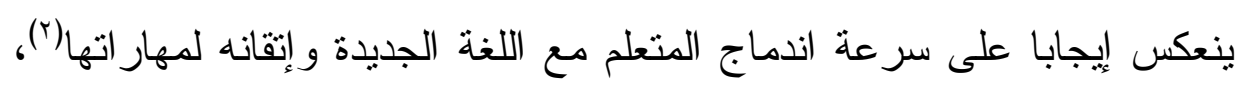

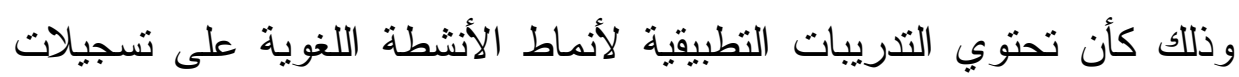

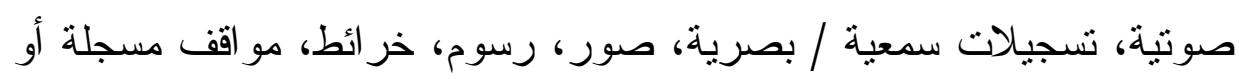

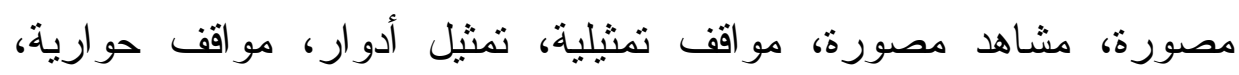

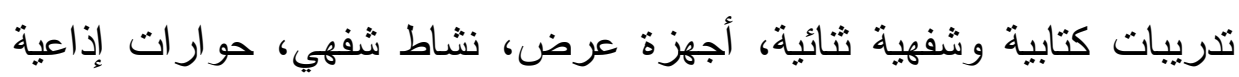

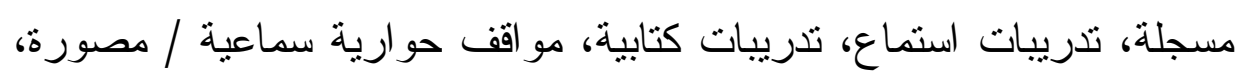

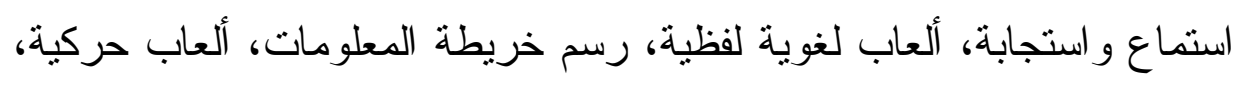

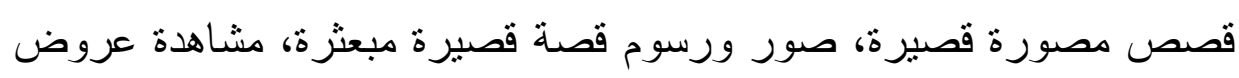
مرئية لإعلانات، أنشطة شفهية كتابية، أنشطة قر ائية.

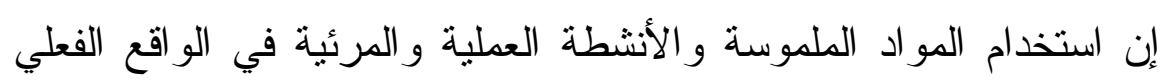

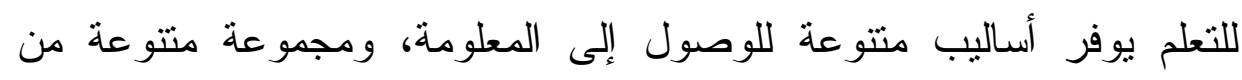
الطرق متعددة الحو اس من أجل التعلم. نماذج من تطبيقات أنثطة المهارات اللغوية بحسب أنماط التعلم السمعية و البصرية و الحركية: - انظر إلى الصور و أكمل الكلمات / انظر إلى الصور ثم اكتب ثلاث جمل عن كل شخص .

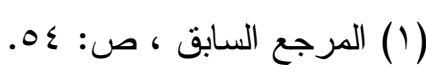

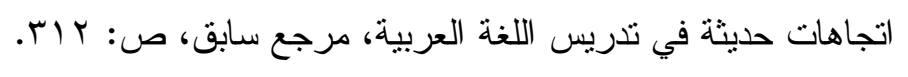


د · خالا محمد حسين اليوبي لـ

- انظر إلى الصور ، ثم تحدث عما سوف يحدث ـ استخدم الفعل الذي يصاحب كل صورة .

- انظر إلى الصور ، ثم اكتب قصة مستعينا بالكلمات التي تحت الصور • - انظر إلى الصور ، و أكمل الحوار بالعبار ات التي في الصندوق • - انظر إلى الصورة و أكمل لعبة الكلمات المتقاطعة بأعضاء الجسم . - انظر إلى الخريطة، ضع علامة على الطريق الذي يسلكه عمر كما فهمت من - النص - انظر إلى القائمة ( الصور ) ووائم بين الصورة ( القائمة ) و المفردات /

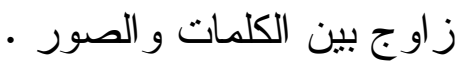

- انظر إلى الصورة و انطق الكلمة / انظر إلى الصورة و اقر أ الكلمات. - استمع إلى الكلمة وضع علامة ( ل ل) بجانب الصورة المناسبة ( اختيار من متعدد) (1)

- استصع ، ثم اختر الصورة التي تدل على العبارة الصحيحة بوضع دائرة حول

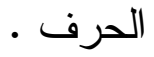

- استمع إلى الجملة ثم ضع خطا تحت الصورة المناسبة. - استمع إلى المحادثة مرتنين وانظر إلى الصور، ثم رثب الصور بحسب التسلسل الذي جاءت به في المحادثة (صور تعبر عن المحادثة ). -صل بين كل صورتين تبدآن بنفس الصوت. -ضع علامة ( ل ) أمام الصورة التي تتنمل على الصوت المذكور . - اقر أ القصة المصورة ، و أجب عن الأسئلة / اقر أ القصة المصورة ( صور + كلمات ) ثم أعد كتابة القصة بالكلمات فقط . - اقرأ التوجيهات التي في الصندوق ، ثم اكتب كل توجيه تحت الصورة المناسبة . - انظر و اقر أ ( كلمات متضادة مصورة ). 
- انظر إلى الصور و اقر أ الكلمات ( ظروف المكان ) ).

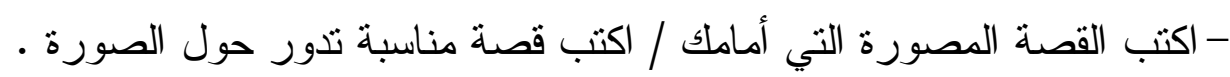

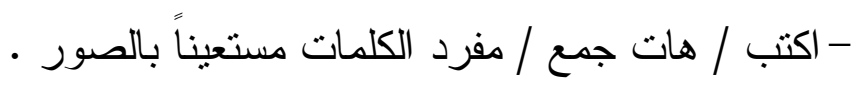

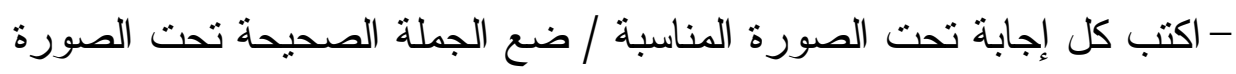
المناسبة لها .

- أعد كتابة الحروف لنكوين كلمات تعبر عن كل صورة .

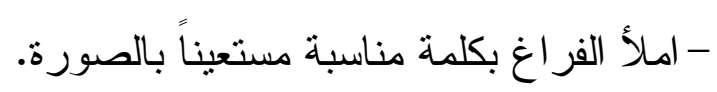

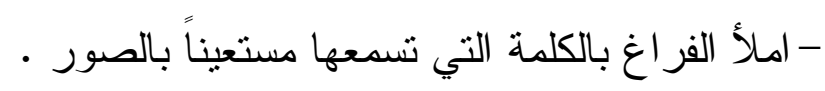

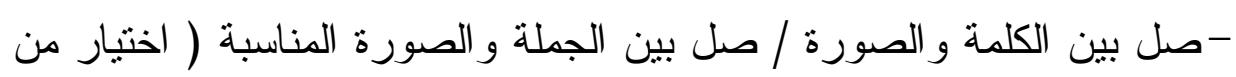
تعدد ).

- و ائم بين الصورة و المهنة / و ائم بين الصورة و الكلمات، مثال : قديم، جديد /

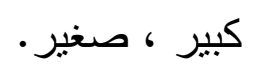

- اربط بشكل مناسب بين النوجيهات و إنثار ات المرور .

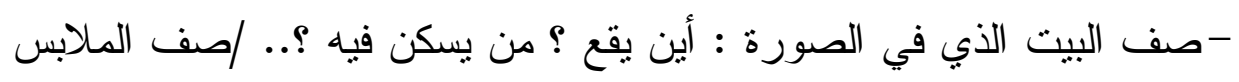

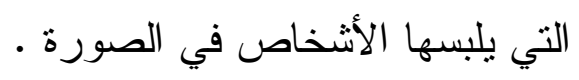

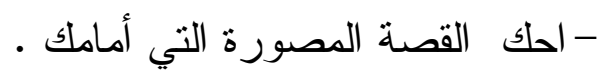

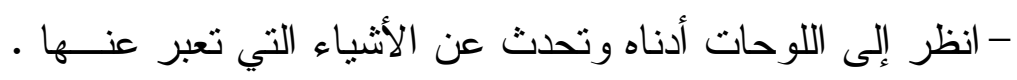

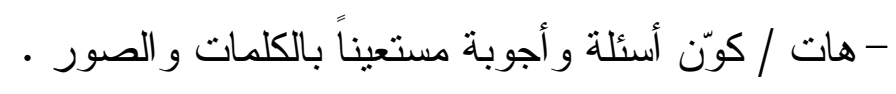

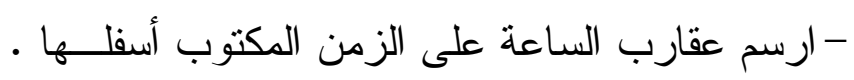

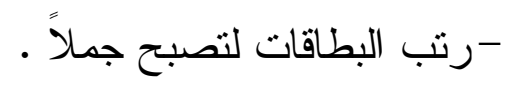
- استخدم المواقف التالية لتمثيل الأدو ار التالية . - استخدم الخريطة المرفقة لتوجه صديقك إلى المكان الذي يريده . 
تالي

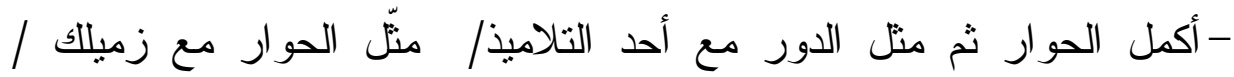
زملائك .

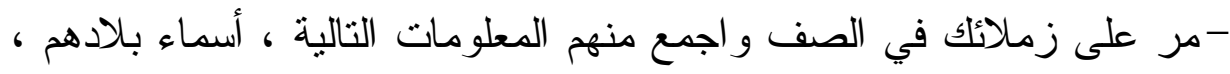

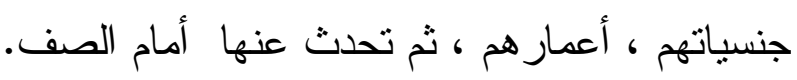


نتوزع الأنشطة اللغوية بحسب مكان إقامتها إلى أنشطة صفية وأخرى لا

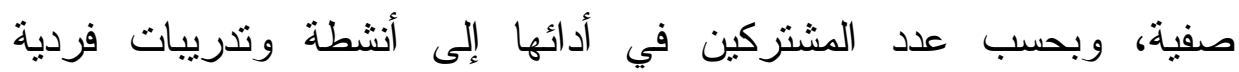
وجماعية، وهي تعد أحد أبرز الأساليب الفعالة في مجال تعليم اللغة العربية

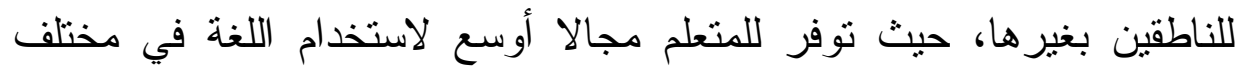

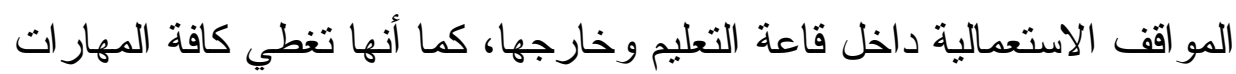
اللغوية بطريقة تفاعلية تو اصلية تكاملية تسعى لتحقيق متعة التعلم لدى المتعلمين على اختلاف مستوياتهم في الفهم و التطبيق. وتؤدي ممارسة الأنثطة اللغوية إلى استدامة مستوى المهارة اللغوية عند متعلم اللغة، كما تساعد على تطوير ها وتتميتها، وقد يختلف مستوى الثأثير بناء على نمط النشاط اللغوي و المهارة المستهدفة. وللأنشطة اللغوية المختلفة أثرها الفاعل في تحقيق أهداف المنهج التعليمي و تمكين التعلم بالممارسة اللغوية التطبيقية، وزيادة دافعية المتعلم نحو التعلم

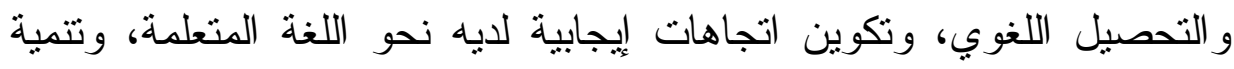

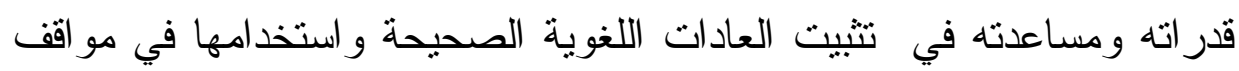
الحياة الطبيعية، وتزداد فاعليتها بمر اعاة ما توصلت إليه النظريات التعليمية

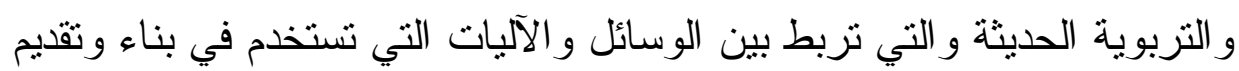
الأنشطة اللغوية وتكييفها وفق الأنماط الدختلفة للمتعلمين. 
- الأنشطة اللغوية: أنواعها-معاييرها- استخداماتها، علي سعد جاب الله

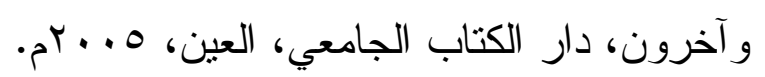

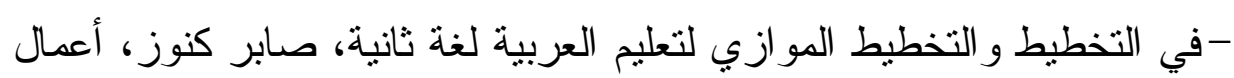

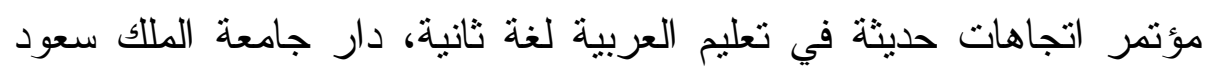

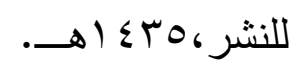

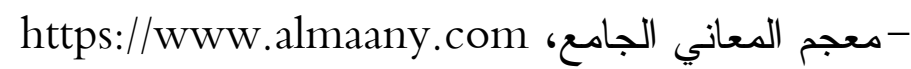

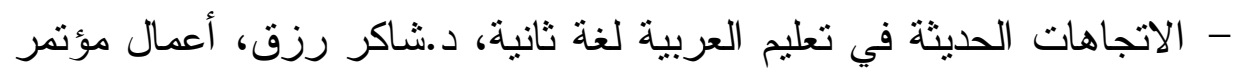

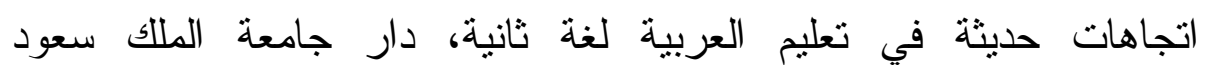

$$
\text { للنشر النه }
$$

- دور القصة القصيرة في تعليم اللغة العربية لغة ثانية، فاطمة الكحلاني،

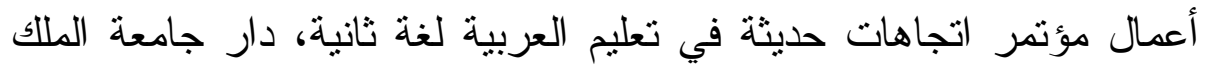

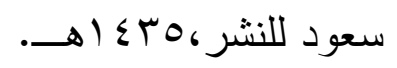

- لسانيات التلفظ وتعليم العربية لغة ثانية، الطيب دبة، أعمال مؤتمر اتجاهات

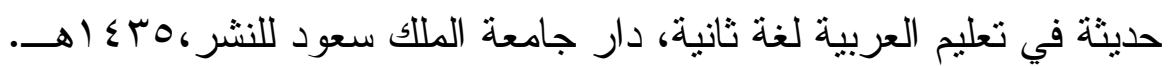

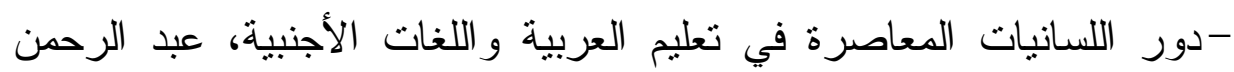

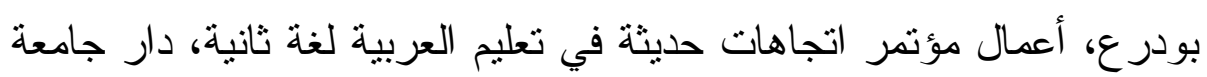

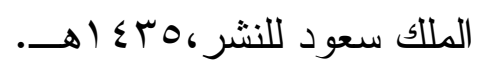

- في التخطيط و التخطيط الموازي لتعليم العربية لغة ثانية، صابر كنوز ، أعمال

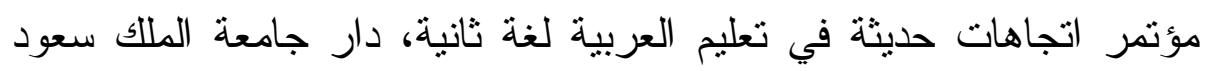

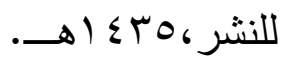

-وثثقة بناء منهج تعليم اللغة العربية لغير الناطقين بها، إعداد قسم تعليم اللغة

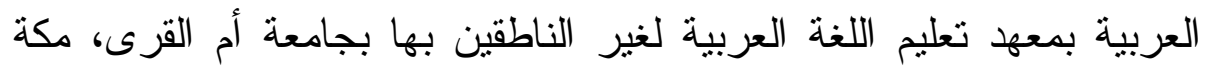




\section{أنماط الأشطة اللغوية}

- المهار ات اللغوية: مستوياتها، تدريسها، صعوباتها، رشدي طعيمة، دار الفكر

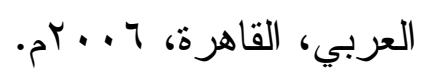

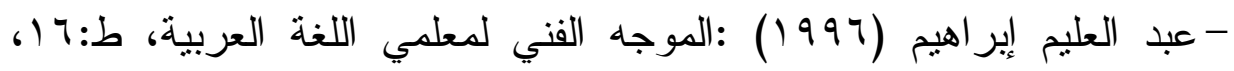

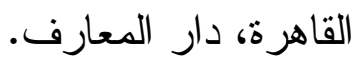

- اتجاهات حديثة في تدريس اللغة العربية، طه الدليمي وسعاد الوائلي، جدار الكاردا للكتاب العالمي، 9 ج. . بم، عمان، الأردن.

- تتمية مهار ات القراءة و الكتابة، حاتم البصيص، جابن، الردن، جامعة حمص، سوريا،

$$
\text { . r. v }
$$

- تعليم المفردات اللغوية، ماهر شعبان عبد الباري، دار المسيرة للنشر

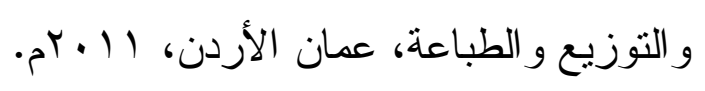

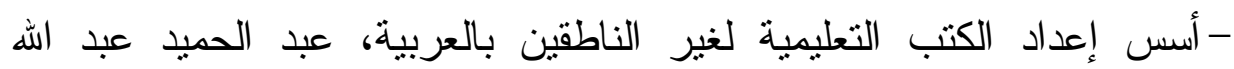

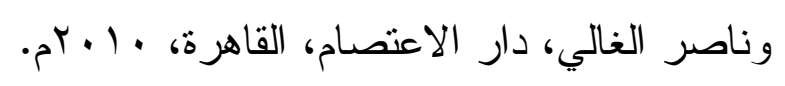

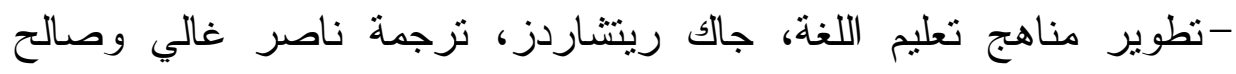

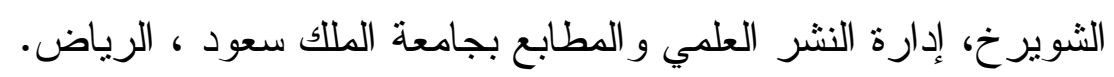

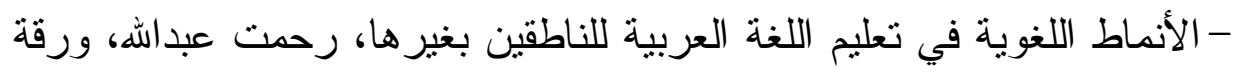

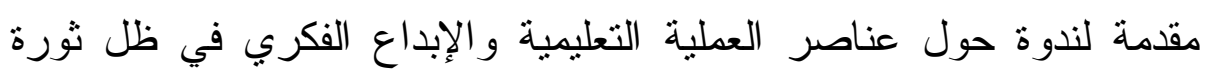
المعلومات، الجامعة الإسلامية بماليزيا، V.....، الثبكة العنكبوتية الدولية

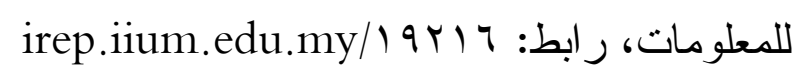
- ملامح النحو العربي في برنامج تعليم العربية للناطقين بغيرها، عبد الحليح

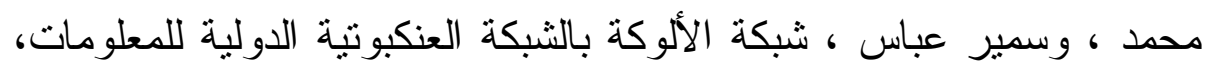

رابط www.alukah.net

- المهارات اللغوية: مستوياتها، تدريسها، صعوباتها، رشدي أحمد طعيمة ،

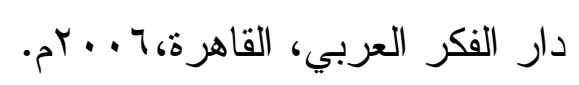




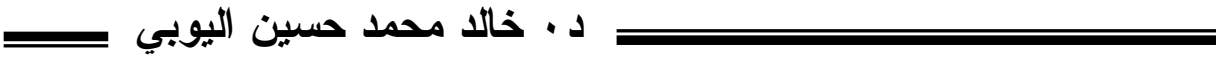

-تعليم اللغة العربية لغير الناطقين بها في ضوء المناهج الحديثة، مختار الطاهر حسين.

- الابتكار في اللغة العربية بين التربية والتعليم والتعلم، أنور طاهر رضا، دار غيداء للنشر و التوزيع، عمان، الأردن. -طرق تدريس اللغة العربية، جودت الركابي، دار الفكر، دمشق، 997 ام. - مهار ات الاستماع النشط، ماهر عبد الباري، دار المسيرة، عمّان، ل| (بام، ص: •11.

-مهار ات الاستماع اللازمة: مفهومها، أهميتها، أهداف تدريسها، أساليب

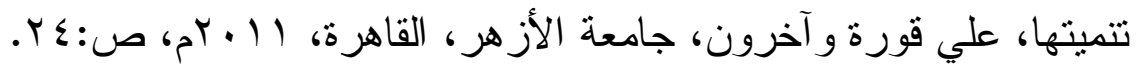
- تدريس اللغة العربية للناطقين بغيرها: مناهج تدريس الاستماع بين النظرية و التطبيق، محمد بونجمة، المغرب، جامعة الأخوين، سا ب بام.

-تعليم اللغة اتصاليا بين المناهج والاستر اتيجيات، رشدي طعيمة ومحمود الناقة، المنظمة الإسلامية للتزبية و التقافة و العلوم، الرباط، ج ـ . ب م.

- McDonough, Steven. H.(199५): Psychology in foreign language teaching. LondonBrown, Steven $(Y\urcorner$.$) : Teaching$ Listening. Cambridge University Press.

- Grabe, W. (Y. . 9). Reading in a Second Language.

Cambridge: Cambridge University Press.

- Mendelsohn, D.J., \& Rubin, J. (1990). A guide for the teaching of second language listening. San Diego, CA: Dominic Press.

- Celce-Murcia (Ed.), Teaching English as a second or foreign language (pp. $\wedge 1-1 \cdot 7)$. Boston, MA: Heinle \& Heinle. 


\section{=}

- Nation, I. S.P. ( ... ). Learning Vocabulary in Another Language. Cambridge, Cambridge University Press.

- Pennsylvania Department of Education $(\uparrow \cdot \mathcal{H} \cdot)$ : Academic Standards for Reading, Writing, Speaking and Listening.

- Richards, Jock C. ( $\ldots$. A): Teaching Listening and Speaking: From Theory to Practice. Cambridge University Press. 